NBER WORKING PAPER SERIES

\title{
GEOGRAPHIC CONCENTRATION IN \\ U.S. MANUFACIURING INDUSTRIES: \\ A DARTBOARD APPROACH
}

Glenn Ellison

Edward L. Glaeser

Working Paper No. 4840

\author{
NATIONAL BUREAU OF ECONOMIC RESEARCH \\ 1050 Massachusetts Avenue \\ Cambridge, MA 02138 \\ August 1994
}

We would like to thank Richard Caves, Sara Fisher Ellison, Bill Miracky, Wally Mullin, Peter Reiss and José Scheinkman for helpful comments, and Matt Botein, Rajesh James, Bruce Sacerdote and Jacob Vigdor for research assistance. Both authors thank the National Science Foundation (SBR-9310009 and SBR-9309808) and the Harvard Clark Fund for financial support. This paper is part of NBER's research program in Growth. Any opinions expressed are those of the authors and not those of the National Bureau of Economic Research.

(C) 1994 by Glenn Ellison and Edward L. Glaeser. All rights reserved. Short sections of text, not to exceed two paragraphs, may be quoted without explicit permission provided that full credit, including () notice, is given to the source. 


\title{
GEOGRAPHIC CONCENTRATION IN \\ U.S. MANUFACTURING INDUSTRIES: A DARTBOARD APPROACH
}

\begin{abstract}
This paper discusses the prevalence of Silicon Valley-style localizations of individual manufacturing industries in the United States. Several models in which firms choose locations by throwing darts at a map are used to test whether the degree of localization is greater than would be expected to arise randomly and to motivate a new index of geographic concentration. The proposed index controls for differences in the size distribution of plants and for differences in the size of the geographic areas for which data is available. As a consequence, comparisons of the degree of geographic concentration across industries can be made with more confidence. We reaffirm previous observations in finding that almost all industries are localized, although the degree of localization appears to be slight in about half of the industries in our sample. We explore the nature of agglomerative forces in describing patterns of concentration, the geographic scope of localization, and the extent to which agglomerations involve plants in similar as opposed to identical industries.
\end{abstract}

Glenn Ellison Department of Economics Massachusetts Institute of Technology 50 Memorial Drive Cambridge, MA 02139
Edward L. Glaeser Department of Economics 113 Littauer Center Harvard University Cambridge, MA 02138 and NBER 


\section{Introduction}

The concentration of the computer industry in Silicon Valley and of the auto industry in Detroit are two of the more famous examples of the geographic agglomeration of firms in a single industry. The economics literature motivated by these examples is both old and vibrant. Agglomerations have for years drawn the attention both of urban planners with practical concerns and of economists who wish to understand them simply because they are a striking feature of the economic landscape. More recently, they have been regarded also as a potentia! source of insights into the nature of the increasing returns and external economies which drive the new theories of growth and international trade. As a result, researchers primarily interested in international trade, growth, industrial organization, and business strategy have joined geographers and urhan economists in investigating geographic concentration. $^{1}$

This paper is concerned with measurement issues relevant to work in all these fields. Our "dartboard approach" to studying concentration consists essentially of extending the analogy of firms choosing locations by throwing darts at a map into a useful set of models of location choice in the presence of agglomerative forces. In doing so, we have two main goals. First, we wish to look formally at whether most industries are truly localized. Second, and more importantly, we wish to use the models to guide the development of new tools for the measurement of localization. We hope that the index of localization we propose will facilitate future research into a range of topics involving cross-industry comparisons, e.g. how patterns of agglomeration compare in different countries, how levels of concentration have evolved over time, and whether cross-industry patterns provide insights into the nature of the forces which cause agglomeration.

That Silicon Valley-style agglomerations may be more the rule than the exception has been noted by a number of authors (see e.g. Krugman (1991a)). Our first goal is to provide a careful reexamination of whether this is indeed the case. The defining characteristic of our dartboard approach (and the motivation for a reexamination) is that we wish to reserve the term "localized" for industries exhibiting levels of concentration beyond those which would be observed if firms had chosen the locations of their plants in a completely random manner. In doing so, we take as exogenous the discreteness of plants. ${ }^{2}$ For example, in the U.S. vacuum cleaner industry (S.I.C. 3635) about $75 \%$ of the employees work in one of the four largest plants. Given this, we do not want to regard the industry as being

\footnotetext{
'For samples of work in these fields see Florence (1948), Hoover (1948), Fuchs (1962), Carlton (1983), Henderson (1988), Earight (1990), Porter (1990), Krugman (19912), and Jaffe et. al. (1993).

${ }^{2}$ We do not mean to say that the determinantion of plant sizes is not a topic with interesting implications for understanding increasing returns, juat that it is usefully separated from the measurement of interplant agglomeration.
} 
localized simply because $75 \%$ of its employment is contained in four states. Also, even if firms did choose locations for their plants by throwing darts at a map, one should recognize that several of the plants by chance might appear to form a cluster. ${ }^{3}$ Our use of the term geographic concentration is further restricted in that we will regard an industry as concentrated only if it displays some agglomeration beyond the overall concentration of U.S. manufacturing. ${ }^{4}$ For example, we do not want to call the newspaper industry concentrated just because $12 \%$ of all employment in the industry is in California and an additional $9 \%$ is in New York. Despite this more stringent definition of localization, our results strikingly reaffirm the belief that localization is widespread.

Our primary focus in this paper is on the development of a new index (and other tools) for the measurement of the degree to which industries are geographically concentrated. We beljeve that a useful index of geographic concentration must have two properties: it must measure something which is interesting to economists and allow one to make comparisons across industries. Such comparisons are not only of descriptive interest, but are the substance of most inquiries into the nature of geographic concentration. ${ }^{s}$ Interindustry (or intertemporal) comparisons are problematic with previously defined indices because the comparisons are greatly affected (in ways which are not completely understood) by variations in industry characteristics and data availability. ${ }^{6}$

We motivate our index with an analysis of two models of location choice: one based on the idea that spillovers (e.g. localized knowledge spillovers ${ }^{7}$ ) may lead firms to wish to locate together, and the other based on the idea that firms want to locate wherever some type of natural advantage (e.g. access to raw materials) is present. Both models are capable of accounting for geographic concentration, and they are likely important to varying degrees

\footnotetext{
${ }^{3}$ In fact, one only needs to throw 6 darts at a map of the U.S. before it is most likely that at least two will hit in some state. Such random agglomerations would be less likely to occur if transportation cosis or other "centrifugal" lorces give firms a desire to locate away from their compelition.

'We thus use the term as a synonym for what Henderson (1988) and Krugman (1991a) call localization as opposed to what they term urbanization or geographic concentration. We hope that our use of localization and geographic concentration as interchangeable terms does not create confusion. Again, we do not wish to imply that the overall agglomeration of industries is not an interesting topic, just that it is usefully separated from an examination of intraindustry agglomeration.

'For example, Krugman (1991a) discusses whether high tech industries are more concentrated than other industries to investigate the importance of knowledge spillovers and compares the U.S. auto industry with its European counterpart to discuss the potential impact of European integration. Earlier comparative works include Florence's (1948) study of U.S. and British industries and Fuchs's (1962) discussion of changes in the U.S. between 1929 and 1954.

'A representative set of these indices are those of Creamer (1943), Florence (1948), Enright (1990) and Krugman (1991a). Florence's observation that industries with larger plants are more concentrated is a particulariy clear exampie of the difficulties in interpreting comparisons.

'See Krugman (1991b) for a discussion of other spillovers.
} 
in different industries. (Our best example of natural advantage is the wine industry where it is difficult to separate manufacturing from the growing of grapes and $78 \%$ of employment is in California. Our best example of spillovers is the fur industry where 334 plants in New York (most in Manhattan) employ $77 \%$ of the industry's workforce. ${ }^{8}$ ) The main point of our analysis is not that these models can both account for geographic concentration, but rather that regardless of which mechanism generates geographic concentration in a particular industry we can control for the number and size distribution of plants and for the set of geographic areas for which data is available in the same way. It is because of this coincidence that we feel somewhat comfortable that our index may control for these factors in the real world as well.

While the paper is concerned largely with methodology, we try also to provide as detailed a description as space allows of geographic concentration in U.S. manufacturing industries. ${ }^{9}$ After all, the ultimate test of an index is whether it provides enlightening results. First, we discuss overall levels of concentration, with one observation being that many industries are only slightly concentrated (with a substantial fraction of what others have identified as concentration being attributable to the discreteness of plants.) Next, we discuss briefly which industries are concentrated. Subsequently, we explore the nature of the spillovers (or other forces) causing agglomeration along a number of dimensions: using data on county, state, and regional agglomeration to investigate the geographical scope; looking at whether their influence is felt within narrowly defined industries or whether these spillovers act more broadly; and examining the degree to which the agglomeration of plants occurs internally within firms.

\section{Models of Location Choice}

In this section we develop several simple models of location choice. These models will be used to construct a test of whether observed levels of geographic concentration are greater than would be expected to occur randomly, and to motivate our subsequent proposal of an index of geographic concentration.

As a practical matter, the data available for measuring geographic concentration typically consists of a breakdown of an industry's total employment by some geographic subunits, e.g. we may find state-by-state employments for an industry in the U.S. or country-by-

\footnotetext{
${ }^{8}$ Fuchs (1957) provides an excellent discussion of the industry.

'The raw data for most of our calculations is from the 1987 Census of Manufactures. We have gone to some length to fill in missing state-industry employment data so that we may analyze the complete sel of manufacturing industries. We have also estimated the Herfindahl indices of the plant size distributions for each 4-digit industry. We hope that this data may prove useful in future work as well.
} 
country employments in the European Community. We therefore consider an abstract model in which a geographic whole (e.g. the U.S.) is divided into $M$ subunits which have shares $x_{1}, x_{2}, \ldots, x_{M}$ of aggregate employment. We assume the shares $s_{1}, s_{2}, \ldots, s_{M}$ of a given industry's employment located in each of these subunits are also available. With such data, a natural measure of the degree to which employment in the industry departs from the overall pattern of employment is

$$
g=\sum_{i=1}^{M}\left(s_{i}-x_{i}\right)^{2} .
$$

We feel that such a measure is of economic interest in that it emphasizes departures which involve significant fractions of an industry's employment. We will focus on modifications of this measure throughout this paper both because the measure is of economic interest, and because it will prove easier to work with than, say, Gini coefficients. ${ }^{10}$

\subsection{A Simple Model}

We begin with a simple model we will use to ask whether the concentration of employment within industries is greater than would be expected if all plants were located in an independent random manner. We view the "random" choice of the model as reflecting what would be expected in an industry lacking both agglomerative forces (such as spillovers) and centrifugal forces (such as transportation costs with dispersed demand).

Consider an industry consisting of $N$ business units having shares $z_{1}, z_{2}, \ldots, z_{N}$ of the industry's employment. We write $H$ for the industry Herfindahl index" defined by $H=$ $\sum, z_{j}^{2}$. Suppose that each business unit chooses a single location for all of its operations within a country which is divided into $M$ geographic areas having shares $x_{1}, x_{2}, \ldots, x_{M}$ of total employment. ${ }^{12}$ As a model of random location, we imagine that each business unit chooses a single location for all of its employees by throwing a dart at the map of the country. Formally, we suppose that the geographic areas in which the firms choose to locate are independent identically distributed random variables $v_{1}, v_{2}, \ldots, v_{N}$, each taking on the values $1,2, \ldots, M$ with probabilities $p_{1}, p_{2}, \ldots, p_{M}$. We can think of the probabilities $p_{1}, p_{2}, \ldots, p_{M}$ as describing the relative sizes of the states on the map. In trying to test whether this model can describe the geographic concentration of U.S. industries, we will

\footnotetext{
${ }^{10}$ Florence (1948) provides a lengthy argument for a similar measure.

"Note that our definition differa from the conventional use of the term both in that we will usually think of plants rather than firms as the business units in question and in that market shares are shares of employment rather than shipments.

${ }^{17}$ We think of the industry as being smal relative to the country so that the $\left\{x_{i}\right\}$ can be treated as fixed regardless of the location decisions of the business units in the industry.
} 
usually take $p_{i}=x_{i}$ for all $\mathrm{i}$, so that the random location process would on average produce a pattern of employment shares for the industry matching that we have assumed to prevail in the aggregate. ${ }^{13}$

Let us now examine the degree of localization such a model would produce. The fraction of the industry's employment located in geographic unit $i$ is

$$
s_{i}=\sum_{j=1}^{N} z_{j} u_{j i},
$$

where $u_{j i}$ is the Bernoulli random variable equal to one if and only if $v_{j}=i$. Define a normalized measure, $G$, we will refer to as the raw geographic concentration of the industry by

$$
G=\frac{\sum_{i}\left(s_{i}-x_{i}\right)^{2}}{1-\sum_{i} x_{i}^{2}}
$$

Proposition 1 characterizes the raw geographic concentration produced by this model. The fact that we get such a simple answer with the expected value of $G$ depending only on $H$ and not on any details of the plant size distribution is not only interesting, but also useful in that detailed data on plant sizes may be hard to come by.

Proposition 1 In the model above,

$$
E(G)=\frac{1-\sum_{i} p_{i}^{2}}{1-\sum_{i} x_{i}^{2}} H+\frac{\sum_{i}\left(p_{i}-x_{i}\right)^{2}}{1-\sum_{i} x_{i}^{2}}
$$

For $\left(p_{1}, \ldots, p_{M}\right)=\left(x_{1}, \ldots, x_{M}\right)$ this reduces to

$$
E(G)=H
$$

\section{Proof}

The result follows from a straightforward calculation using the fact that the expectation of a sum of random variables is the sum of the expectations regardless of whether the random variables are independent.

$$
\begin{aligned}
\left(1-\sum_{i} x_{i}^{2}\right) E(G) & =E\left(\sum_{i}\left(s_{i}-x_{i}\right)^{2}\right) \\
& =\sum_{i} E\left(\left(s_{i}-p_{i}+p_{i}-x_{i}\right)^{2}\right) \\
& =\sum_{i} \operatorname{Var}\left(s_{i}\right)+\sum_{i}\left(p_{i}-x_{i}\right)^{2} .
\end{aligned}
$$

\footnotetext{
${ }^{13}$ We emphasize that by doing so we are taking as given the concentration of aggregate employment, even though this may be thought of as resulting from (nonindustry-specific) interfirm spillovers. We are interested in exploring intra-industry localizations, not in the fact that there is virtually no manufacturing in the state of Wyoming.
} 
Using $s_{i}=\sum_{j} z_{j} u_{j i}$ and that the $u_{j i}$ for $j=1,2, \ldots, N$ are independent Bernoulli random variables we have

$$
\begin{aligned}
\left(1-\sum_{1} x_{i}^{2}\right) E(G) & =\sum_{i} \sum_{j} z_{j}^{2} \operatorname{Var}\left(u_{j i}\right)+\sum_{i}\left(p_{i}-x_{i}\right)^{2} \\
& =\sum_{i} \sum_{j} z_{j}^{2} p_{i}\left(1-p_{i}\right)+\sum_{i}\left(p_{i}-x_{i}\right)^{2} \\
& =H\left(1-\sum_{i} p_{i}^{2}\right)+\sum_{i}\left(p_{i}-x_{i}\right)^{2}
\end{aligned}
$$

as desired.

QED.

To help get some intuition for this result, it may help to note why it holds in a couple of limiting cases (assuming that $p_{i}=x_{i}$ for all $i$ ). First, for any fixed set of geographic areas, the limit as $H \rightarrow 0$ describes an industry with an infinite number of small firms. In this case the law of large numbers dictates that a fraction $x_{i}$ of the industry's employment will be in geographic unit $i$ and $G$ will be zero. Next, for any fixed firm size distribution imagine that the sizes of the geographic areas become arbirarily small, i.e. let $M \rightarrow \infty$ with $\max _{i} x_{i} \rightarrow 0$. With only a finite number of firms we can in the limit ignore the probability of two darts hitting any geographic unit. The value of $\left(s_{i}-x_{i}\right)^{2}$ will then be approximately $z_{j}^{2}$ if business unit $j$ is located in area $i$ and 0 otherwise. Hence, we can see that the sum of squared deviations will approach the Herfindahl index.

The result also gives us our first intuitive interpretation of a measure of concentration. If an industry has raw concentration $G$, we can think of the distribution of employment in the industry as being as concentrated as would be expected if $\frac{1}{G}$ randomly selected locations each had a fraction $G$ of the industry's employment.

In testing whether a set of industries exhibits excess geographic concentration, it is useful also to know the variance of $G$ in this model. The expression is not as simple as that for the expectation, and depends also on the fourth moment of the distribution of business unit sizes.

Proposition 2 For $\left(p_{1}, p_{2}, \ldots, p_{M}\right)=\left(x_{1}, x_{2}, \ldots, x_{M}\right)$ in the model above $\operatorname{Var}(G)=\frac{2}{\left(1-\sum x_{i}^{2}\right)^{2}}\left(H^{2}\left(\sum x_{i}^{2}-2 \sum x_{i}^{3}+\left(\sum x_{i}^{2}\right)^{2}\right)-\sum_{j} z_{j}^{4}\left(\sum x_{i}^{2}-4 \sum x_{i}^{3}+3\left(\sum x_{i}^{2}\right)^{2}\right.\right.$

The result follows from a straightforward but tedious calculation, which we omit. 


\subsection{Two Models of Localization}

We now discuss two additional models of the location decision process, each of which is capable of explaining localization in excess of that predicted in the simple model above. The models will thus be useful in developing an index of the extent to which an industry exhibits excess geographic concentration.

The models concern location choices which are influenced not only by aggregate employment, but also by the "natural advantages" to locating in certain areas and by localized intraindustry "spillovers." In order to discuss how these factors should be incorporated, it is helpful first to recast the dartboard model of the previous section in more economic terms. Specifically suppose that in an industry like that described above, each business unit locates in whichever state maximizes its profits, and that the profits received by the $k^{\text {th }}$ unit when it locates in area $i$ take the form

$$
\log \pi_{k i}=\log \bar{\pi}_{i}+\epsilon_{k i 1}
$$

where $\overline{\pi_{i}}$ is a measure of the average profitability of area $i$ and $\epsilon_{k i}$ is a random variable reflecting idiosyncratic elements of the suitability of the area to the firm in question (because of fixed firm characteristics, preferences of its management, the success of its search for a site, etc.). If we assume that the $\left\{\epsilon_{k i}\right\}$ are independent and have the Wejbull distribution, then it is a standard result that firm $k$ 's location $v_{k}$ is a random variable with

$$
\operatorname{Prob}\left\{v_{k}=i\right\}=\frac{\overline{\pi_{i}}}{\sum_{j} \bar{\pi}_{j}} \cdot 14
$$

Our standard dartboard model can be obtained as a special case by assuming that the states have no distinguishing features which affect their average profitability other than differences in aggregate employment, and that the positive spillover of aggregate employment on profits takes the form $\bar{\pi}_{i}=x_{i}$. With this specification

$$
\operatorname{Prob}\left\{v_{k}=i\right\}=\frac{x_{i}}{\sum_{j} x_{j}}=x_{i}
$$

Because this dependence of average profits on aggregate employment leads to location choices which on average recreate aggregate agglomeration given the error structure we have assumed, we shall take it as a starting point for our subsequent models. ${ }^{15}$

\footnotetext{
"See McFadden (1973).

${ }^{13}$ Rather than thinking of this dependence as reflecting aggregate spillovers, it is aiso possible to obtain such a relation indirectly by asuming that the profitability at each potential site is independent and exante identical, but that larger states bave more sites to choose from (proportionally to their sggregate employment) so that the best location in a larger state is on average superior.
} 


\subsubsection{A Model of Natural Advantage}

Our first model of industry localization is motivated by the observation that the business units in an industry will appear to be clustered whenever their location decisions are influenced by factors which can be regarded as giving a "natural" advantage to certain of the geographic areas. Our prototypical example is the wine industry. Clearly, the localization of the industry in is in large part due to California's climatic natural advantage in growing grapes. Similarly, the concentration of industries which import or export bulky commodities in coastal states reflects a natural advantage in access to transportation. ${ }^{16}$ Perhaps because such factors so straightforwardly lead firms to cluster together they have generally received less attention than spillovers in discussions of industry localization. They are, however, an essential component of a complete description of agglomeration.

The simplest way to add natural advantage to the location choice model described above is to assume that firm $k$ 's profits when it locates in state $i$ are again of the form

$$
\log \pi_{k i}=\log \overline{\pi_{i}}+\epsilon_{k i},
$$

but with the average profitability of state $i, \pi_{i}$, now taken to be a nonnegative randorn variable reflecting all of the ways in which nature has chosen to make state $i$ unique (which affect profits in the same way for all plants). Conditional on a realization of the $\left\{\bar{\pi}_{i}\right\}$, the probability that each business unit locates in state $i$ is

$$
p_{i} \equiv \frac{\overline{\pi_{i}}}{\sum_{j} \overline{\pi_{j}}} \text {. }
$$

The larger are the differeces between the $p$ 's and the $x$ 's, the more we can think of locational patterns as being influenced by natural advantage.

We analyze a specification of this model in which the importance of natural advantage is neatly parameterized by a single constant $\gamma_{0} \in[0,1]$, by assuming that the state profit levels $\left\{\bar{\pi}_{i}\right\}$ are independent of the $\left\{\epsilon_{k i}\right\}$, and that their distribution is such that $E\left(p_{i}\right)=x_{i}$ and $\operatorname{Var}\left(p_{i}\right)=\gamma_{0} x_{i}\left(1-x_{i}\right){ }^{17}$ Note that when $\gamma_{0}=0$, there are no common shocks and we obtain our standard dartboard model of random locations. At the other extreme, when $\gamma_{0}=1$ each $p_{i}$ has the largest possible variance given its mean and support, so that with probability one the differences in state characteristics are so extreme that all business units will cluster in a single state.

To explore the level of raw geographic concentration such a model produces for intermediate $\gamma_{0}$ and how this depends on the structure of the industry, it is helpful to restate

\footnotetext{
${ }^{10}$ One formal study of such an effect is Carlton (1983), which finds that energy prices are an important determinant of plant location decisions in several industries.

${ }^{17}$ For example, one could assume that $\overline{x_{i}}=x_{i}+\eta_{i}$ with the $\left(\eta_{i}\right)$ being mean zero random variables with $\sum_{1} \eta_{1}=0$ (with probability one) and $\operatorname{Var}\left(\eta_{i}\right)=\gamma_{0} x_{i}\left(1-x_{i}\right)$. Another example is given later in this section.
} 
the model using a dartboard metaphor. We can think of the business units' choices of location as a two stage process. In the first stage nature chooses (from some set of possible dartboards) a single dartboard on which the geographic areas have sizes $p_{1}, p_{2}, \ldots, p_{M}$, reflecting the importance and allocation of comparative advantage across the areas (the larger areas being those with greater average profits). In the second stage, all business units, being influenced by the same levels of comparative advantage, independently throw darts at this board to choose their locations.

The following proposition shows that the expected raw concentration is linearly increasing in $\gamma_{0}$ and again depends on the distribution of the plant sizes only through $H$.

Proposition 3 In the two stage model of companative advantage described above

$$
E(G)=\gamma_{0}+\left(1-\gamma_{0}\right) H
$$

\section{Proof}

Using the result of Proposition 1 we have

$$
\left(1-\sum_{i} x_{i}^{2}\right) E(G)=E_{p}\left(\left(1-\sum_{i} p_{i}^{2}\right) H+\sum_{i}\left(p_{i}-x_{i}\right)^{2}\right) .
$$

We have assumed that $E\left(p_{i}\right)=x_{i}$, and $\operatorname{Var}\left(p_{i}\right)=\gamma_{0} x_{i}\left(1-x_{i}\right)$. Hence,

$$
\begin{aligned}
\left(1-\sum_{i} x_{i}^{2}\right) E(G) & =H\left(1-\sum_{i} x_{i}^{2}+\gamma_{0} x_{i}\left(1-x_{i}\right)\right)+\sum_{i} \gamma_{0} x_{i}\left(1-x_{i}\right) \\
& =H\left(1-\gamma_{0}+\left(\gamma_{0}-1\right) \sum_{i} x_{i}^{2}\right)+\gamma_{0}\left(1-\sum_{i} x_{i}^{2}\right) \\
& =\left(1-\sum_{i} x_{i}^{2}\right)\left(\left(1-\gamma_{0}\right) H+\gamma_{0}\right)
\end{aligned}
$$

as desired.

QED.

For concreteness, it may help to note that one specification satisfying the conditions above is obtained by assuming that the $\left\{\bar{\pi}_{i}\right\}$ are independent random variables with $\bar{\pi}_{i}$ having a chi-square distribution with $2 \frac{1-\gamma_{0}}{\gamma_{0}} x_{i}$ degrees of freedom. The induced distribution of $p_{i}=\frac{\overline{\bar{x}_{i}}}{\sum_{j} \bar{\pi}_{j}}$ is then $\beta\left(\frac{1-\gamma_{0}}{x_{0}} x_{i}, \frac{1-x_{0}}{x_{0}}\left(1-x_{i}\right)\right)$, and hence has mean $x_{i}$ and variance $\gamma_{0} x_{i}(1-$ $\left.x_{i}\right) .18$

\footnotetext{
${ }^{14}$ More generally the same distribution for $p_{i}$ is obtained whenever $\overline{x_{i}} \sim \Gamma\left(\frac{1-\gamma_{0}}{T_{0}} x_{i}, \lambda\right)$. The joint distribution of $\left(p_{1}, \ldots, p_{M}\right)$ is Dirichlet with parametera $\left(\frac{1-y_{0}}{T_{0}} x_{1}, \ldots, \frac{1-x_{0}}{7_{0}} x_{M}\right)$. See Johnston and Kotz (1972, p. 231) for a description of this distribution. The density function is $f\left(y_{1}, \ldots, y_{M-1}\right)=$ $\Gamma\left(\frac{1-\gamma_{0}}{r_{0}}\right) \prod_{i=1}^{M} \Gamma\left(\frac{1-\gamma_{0}}{r_{0}} x_{i}\right)^{-1} p_{i}^{\frac{1-\gamma_{0}}{\gamma_{0}} x_{i}-1}$.
} 


\subsubsection{A Model of Spillovers}

Our second model of industry localization is motivated by the idea that externalities or spillovers may lead firms to desire to locate their plants near other plants in the industry. We use the term spillovers quite broadly here to refer to technological spillovers, gains from interfirm trade, the effect of local knowledge on the location of spinoff firms, etc. essentially any forces which lead firms to choose locations near other firms in the industry.

To model such factors, one might assume that the profit of business unit $k$ if located in area $i$ is of the form

$$
\log \pi_{k i}=\log \bar{\pi}\left(x_{i}, v_{1}, \ldots, v_{i-1}, v_{i+1}, v_{M}\right)+\epsilon_{k i},
$$

where as before $v_{j}$ is the location of plant $\mathrm{j}$. This formulation allows average profits within a state to be affected generally by both the aggregate employment and the location of the other plants in the industry (but not by state characteristics). To make the analysis tractable and to aid interpretation, we again examine a simple parametric specification of this model. In particular, we consider for $\gamma_{0} \in[0,1]$ profit functions of the form

$$
\log \pi_{k i}=\log \left(x_{i}\right)+\sum_{\ell \neq k} e_{k \ell}\left(1-u_{i i}\right)(-\infty)+\epsilon_{k i},
$$

where the $\left\{e_{k \ell}\right\}$ are Bernoulli random variables equal to one with probability $\gamma_{0}, u_{\ell i}$ is an indicator for whether $v_{\ell}=i$, and the $\left\{\epsilon_{k i}\right\}$ are again independent Weibull random variables independent of the $\left\{e_{k \ell}\right\}$.

To motivate this formulation, note that the first term $\log \left(x_{i}\right)$ is the same dependence of profits on aggregate employment necessary to reproduce (on average) the pattern of aggregate employment. The second expression involves two main assumptions made largely for tractability. First, we have assumed that the effect of plant $\ell$ 's location on plant $k$ 's profit depends only on whether they are in the same area, not on the distance between different areas. Second, rather than assuming a continuous distribution for the magnitude of the spillovers, we take the spillovers to have an extreme two point support - they are either strong enough so that firms $k$ and $\ell$ will have negative infinity profits if they locate apart, or they are nonexistent so that $k$ 's profits are independent of $\ell$ 's location. As the probability that any pair of firms has such a crucial spillover between them, $\gamma_{0}$ clearly indexes the importance of spillovers. ${ }^{19}$

In this spillover model, one needs to be more careful in specifying the decision processes of the business units. We assume the the business units choose locations in some preordained order, and that each firm in turn maximizes its profits conditioning only on the

\footnotetext{
${ }^{19}$ Note that in a violation of accepted practice are using ro to represent a completely different parameter here than in the previous model. We have made this decision to emphasize that the predicted mean concentration of the two models will turn out to be identical.
} 
location decisions of the firms which have moved previously. We shall assume also that the indicator variables $\left\{e_{k \ell}\right\}$ for whether spillovers exist between pairs of firms are symmetric and transitive in the sense that $e_{k \ell}=1 \Rightarrow e_{\ell k}=1$ and $e_{k \ell}=1$ and $e_{\ell m}=1 \Rightarrow e_{k m}=1 .{ }^{20}$ In this case, the process we have specified is a rational expectations equilibrium in which each firm earns nonnegative profits and the resulting distribution of locations is independent of the order in which the business units make their choices. Note that for $\gamma_{0}=0$ the model is again our standard dartboard model, and for $\gamma_{0}=1$ all firms will cluster in a single area.

To analyze the geographic concentration such a model produces it helps again to think of the firms' location choices in terms of a dart throwing metaphor. Each business unit is represented by a dart which will be thrown to choose a location. In the first stage, nature randomly decides to weld some of the darts together into clusters, with the distribution of her decisions being such that each pair of darts has probability $\gamma_{0}$ of being in the same welded cluster. In the second stage, each cluster of welded darts is thrown independently (with all darts in a cluster hitting a single point).

In this model, the business units' locations $v_{1}, \ldots, v_{N}$ are identically distributed random variables, each taking on the value $i \in\{1,2, \ldots, M\}$ with probability $x_{i}$. Note, however, that the $\left\{v_{j}\right\}$ are not independent; instead it is straightforward to show that $\operatorname{Corr}\left(u_{k i}, u_{\ell i}\right)=$ $\gamma_{0}$ for all $i$ and all $\ell \neq k .^{21}$ Proposition 4 characterizes the raw geographic concentration produced by this model.

Proposition 4 In the model of spillovers described above

$$
E(G)=\gamma_{0}+\left(1-\gamma_{0}\right) H .
$$

Proof

$$
\begin{aligned}
\left(1-\sum_{i} x_{i}^{2}\right) E(G) & =\sum_{i} \operatorname{Var}\left(\sum_{j} z_{j} u_{j i}\right) \\
& =\sum_{i} \sum_{j} z_{j}^{2} \operatorname{Var}\left(u_{j i}\right)+\sum_{i} \sum_{j, k, j \neq k} z_{k} z_{j} \operatorname{Cov}\left(u_{k i}, u_{j i}\right) \\
& =\sum_{i} \sum_{j} z_{j}^{2} x_{i}\left(1-x_{i}\right)+\sum_{i} \sum_{j, k, j \neq k} z_{k} z_{j} \gamma_{0} x_{i}\left(1-x_{i}\right) \\
& =\left(1-\sum x_{i}^{2}\right)\left(\sum_{j} z_{j}^{2}+\gamma_{0} \sum_{j, k, j \neq k} z_{k} z_{j}\right) .
\end{aligned}
$$

\footnotetext{
${ }^{20}$ Note that we have not fully specified the joint distribution of the $\left\{e_{k \ell}\right\}$. The proposition below will apply to aلl distributions with the properties above. To see that at least one such joint distribution exists consider the case of the $\left\{e_{k \ell}\right\}$ being perfectly correlated, so that with probability to all the firms are completely interdependeat and with probability 1 - $\gamma_{0}$ all of their profits are independent.

${ }^{21}$ The reader may note that this is the only property of the joint distribution which is necessary lor the proposition, and hence the proposition applies to any formulation of the interdependent profits which induces this correlation in location choices.
} 
The desired result now follows from the substitution $\sum_{j \neq k} z_{j} z_{k}=\left(\sum_{j} z_{j}\right)^{2}-\sum_{j} z_{j}^{2}=1-H$. QED.

The most notable feature of the result in Proposition 4 is that our model of spillovers and our model of natural advantage yield identical functional forms for the relationship between the expected level of geographic concentration and the other industry characteristics (the plant size distribution and the sizes areas for which employment breakdowns are available). This coincidence motivates the index of concentration proposed below. The coincidence of the results of Propositions 3 and 4 also tells us, in some sense, that we cannot distinguish comparative advantage from spillover theories based only on the mean levels of geographic concentration. ${ }^{22}$

Real world location decisions are likely to be affected by both natural advantage and by spillovers, so it is probably worth noting that a combination of the two factors also produces a level of raw concentration which is related to the industry characteristics in the same way. Specifically, consider a three stage model (we give only the dartboard version) where in the first stage Nature chooses $\left(p_{1}, p_{2}, \ldots, p_{M}\right)$ from a distribution with $E\left(p_{i}\right)=x_{i}$ and $\operatorname{Var}\left(p_{i}\right)=\gamma_{1} x_{i}\left(1-x_{i}\right)$; in the second Nature randomly welds each pair of darts with probability $\gamma_{2} ;$ and in the third the welded clusters are independently thrown at a dartboard in which the states have sizes $\left(p_{1}, p_{2}, \ldots, p_{M}\right)$.

Proposition 5 In the three stage model above

$$
E(G)=\gamma_{0}+\left(1-\gamma_{0}\right) H
$$

with $\gamma_{0}=\gamma_{1}+\gamma_{2}-\gamma_{1} \gamma_{2}$.

The proof is similar to those of the previous propositions and is therefore omitted.

\section{An Index of Geographic Concentration}

Suppose we are given data containing the shares $s_{1}, s_{2}, \ldots s_{M}$ of an industry's employment in each of $M$ geographic areas, the shares $x_{1}, x_{2}, \ldots, x_{M}$ of total employment in each of those areas, and the Herfindahl index $H=\sum_{j=1}^{N} z_{j}^{2}$ of the industry plant size distribution.

\footnotetext{
${ }^{22}$ The theories will differ in their predictions for higher moments of $G$. Recall, however, that we have not fully specified either model (leaving out the bigher moments of the \{ $\left.p_{i}\right\}$ in the natnral advantage model and the full joint distribution of the $\left\{e_{n}\right\}$ in the spillover model). Varying these elements, each model can produce a range of predictions for $\operatorname{Var}(G)$. For this reason, we do not feel that attempts to distinguish the theories on such grounds will be fruitful.
} 
As a convenient index of the degree to which an industry is geographically concentrated we propose the use of a measure $\gamma$ defined by

$$
\gamma \equiv \frac{G-H}{1-H} \equiv \frac{\sum_{i=1}^{M}\left(s_{i}-x_{i}\right)^{2}-\left(1-\sum_{i=1}^{M} x_{i}^{2}\right) \sum_{j=1}^{N} z_{j}^{2}}{\left(1-\sum_{i=1}^{M} x_{i}^{2}\right)\left(1-\sum_{j=1}^{N} z_{j}^{2}\right)} .
$$

We believe that this index has a number of attractive features. It reflects a property which is naturally meaningful in emphasizing large deviations from the distribution of aggregate employment. Because $E(\gamma)=0$ when data is generated by our standard dartboard model, it is clearly interpretable as measuring excess concentration beyond that which would be expected to occur randomly. Finally and most importantly the index allows us to easily perform meaningful comparisons of the degrees of concentration in different industries, e.g. comparing a U.S. industry with its counterpart in another country, or comparing concentration using 3 - and 4-digit industry definitions.

To justify such comparisons, we note simply that if the location decision process of plants is accurately described by either or both of the natural advantage and spillover models of the previous section then

$$
E(\gamma)=\frac{E(G)-H}{1-H}=\gamma_{0},
$$

i.e. the index is an unbiased estimator of the fundamental parameter which describes the strength of natural advantage or spillovers. That the index controls for the number and size distribution of plants and (subject to the caveat below) for the sizes of the geographic subunits for which data is available in both of these modes gives us some hope that it will allow us to compare the strength of these forces in real world industries as well.

In making the transition from the models to the real world one caveat is necessary with regard to comparisons based on differing geographic subunits. Each of our models takes an extreme view of the geographic scope of the forces which produce localization. For example, when spillovers are important they are assumed to accrue only if the firms locate in the identical geographic subunit: In practice, spillovers would likely have an effect which declines more smoothly and provides some benefit to locating in nearby areas as well (more so when the areas in question are smaller). If we estimate $\gamma$ using county level data, it will reflect only the added probability of pairs of plants locating in the same county, while a $\gamma$ estimated from state level data will reflect the typically larger increase in the probability of the pair locating in the same state. ${ }^{23}$

\footnotetext{
${ }^{23}$ The location decision process of the natural advantage model depeads heavily on the definition of the subareas, and thus the conditions under which we can compare estimates based on different geographic subunits are less obvious. One case in which such comparisons are completely justified is that of the gamma-
} 
The fact that we can regard $\gamma$ as a parameter estimate clearly suggests that it should be interpreted in light of its standard error. What this standard error is, however, can not be determined given the assumptions we have made so far. In particular, (and we consider it a feature of our paper that this is true) the results on mean concentration above have been derived without ever specifying the higher moments of the $\left\{\bar{\pi}_{i}\right\}$ in the natural advantage model or joint distribution of the indicators $\left\{e_{k \ell}\right\}$ in the spillover model. A straightforward calculation of the standard errors gives

$$
\operatorname{Var}\left(\gamma-\gamma_{0}\right)=\frac{1}{\left(1-H^{2}\right)\left(1-\sum x_{i}^{2}\right)^{2}} \sum_{i, r=1}^{M} \sum_{j, k, l, m=1}^{N} z_{j} z_{k} z_{l} z_{m} \operatorname{Cov}\left(\mu_{j i} \mu_{k i}, \mu_{\ell r} \mu_{m r}\right) .
$$

The covariance terms will depend on the unspecified elements of the models. To give a feel for the magnitude of one of the sources of measurement error in our calculations of $\gamma$ 's, we will present later standard errors (obtained from simulations) from one complete specification - a natural advantage model where the distribution of the $\left(p_{1}, p_{2}, \ldots, p_{M}\right)$ is assumed to be Dirichlet with parameters $\left(\frac{1-\gamma_{0}}{\gamma_{0}} x_{1}, \frac{1-\gamma_{0}}{\gamma_{0}} x_{2}, \ldots, \frac{1-\gamma_{0}}{\gamma_{0}} x_{M}\right) .{ }^{24}$

\section{Data}

By design, the data requirements for this paper are fairly simple. We require the distribution of employment across a set of geographic areas for a set of industries and the Herfindahl indices of firm and plant employment shares for those industries. Our definition of industries is the finest one possible given data availability constraints - the 459 manufacturing industries defined by the 4-digit classifications of the Census Bureau's 1987 S.I.C. system. Given this decision, we settled on the finest geographic areas for which we felt we could obtain reliable employment breakdowns - the 50 states plus the District of Columbia. Our

distributed $\left\{\bar{x}_{i}\right\}$ described at the end of Section 2.2.1. In this model, we can regard natures choice of a dartboard as resulting from an assigament of a probability (or more precisely of an independent gammadistributed $\overline{x_{i}}$ ) to each square inch of the country, with the probability of a dart hitting each state (or other subunit) being obtained by summing the probabilities of its hitting each of the square inch plots within the state. More formally, suppose that geographic area 1 is divided into subareas $11,12, \ldots, 1 r$ with shares $x_{11}, \ldots, x_{1}$ of wotal employment (with $\left.x_{11}+\cdots+x_{1} \equiv x_{1}\right)$. When $\left(p_{11}, \ldots, p_{1,}, p_{2}, \ldots, p_{M}\right)$ is Dirichlet with paramelers $\left(\frac{1-\gamma_{0}}{\gamma_{0}} x_{11}, \ldots, \frac{1-x_{0}}{\gamma_{0}} x_{1}, \frac{1-x_{0}}{x_{0}} x_{2}, \ldots, \frac{1-x_{0}}{x_{0}} x_{N}\right),\left(p_{11}+\cdots+p_{1 r}, p_{2}, \ldots, p_{M}\right)$ is Dirichlet with parameters $\left(\frac{1-\gamma_{0}}{y_{0}} x_{1}, \frac{1-\gamma_{0}}{y_{0}} x_{2}, \ldots, \frac{1-\gamma_{0}}{y_{0}} x_{M}\right)$. Note that this specification is extreme as well in that natural advantages of nearby square inches are likely to be spatially correlated, so again we would expect to find larger $\gamma$ 's when using coarser subdivisions.

"One question of interpretation arises in defining the standard errors. Do we treat $\gamma$ as an estimate of the variance of the ex ante distribution from which the $\left(p_{i}\right)$ are drawn or as an estimate of the ex post realization of $\frac{\sum\left(p_{0}-x_{0}\right)^{2}}{1-\sum x_{i}^{2}}$. We take this latler interpretation, drawing ( $\left.p_{i}\right)$ for which this expression is equal to $\mathrm{g}$ from the conditional distribution induced by the Dirichlet. 
source for all of this data is the 1987 Census of Manufactures, although despite our simple data requirements the process of constructing the data is quite involved. While the data we have filled in is by necessity speculative, we hope that our data may be helpful to others in the future.

Our construction of state-industry employments relies on the Census of Manufactures' listings of state-industry employments and on the reported totals for manufacturing employment in each state and in each 2-, 3-, and 4-digit industry. A very substantial data filling procedure was necessitated by two limitations of the raw data. First, employment in any state-industry with fewer than 150 employees is omitted from the raw data (presumably to save space). Because states with less than 150 employees contain a nontrivial fraction of employment in some industries, it is desirable to fill in these numbers. Second, and more importantly, to protect the confidentiality of individual responses the Census often reports state-industry employment only as falling into one of five categories corresponding to employments of $100-249,250-499,500-999,1000-2500$, and the unfortunately low topcode of $2500+{ }^{25}$ To give some idea of the magnitude of these restrictions, simply setting employment in each of these cells to its lower bound unequivocally identifies the location of $90 \%$ of employment in the median industry and $80 \%$ on average.

To complete our data set, we have filled in data for all 2-, 3-, and 4- digit stateemployments using the census data and the adding up constraints across states within industries and across subindustries within states. Our algorithm is based on the idea of imposing the upper and lower bounds of the reported ranges, and adjusting employments within the ranges to try to satisfy the adding up constraints in both directions. Data for state-industries with less than 150 employees is filled by a similar procedure which uses also the number of "missing" establishments created by the nonreporting of these cells. More details are given in Appendix A. ${ }^{26}$

Throughout most of the paper we will think of plants as the business units of the model, and thus rely on a Herfindahl index $H_{p}$ of the employment shares of plants to control for the size distribution of business units. While the Census does not publish this information it does make available for each 4-digit industry the total employment and the total number of

\footnotetext{
${ }^{25}$ Fortunately, employment in many topcoded cells is relatively small, because the largest state employments tead to occur in states with several firms so that withholding reatrictions do not apply.

${ }^{30}$ An alternate approach used by several past authors, e.g. Enright (1990), is to reduce the number of topcodes by obtaining data from the County Business Patterns (which does not have an identical sample, but which has a much higher topcode) and use means of ranges, dropping industries where topcodes can not be avoided or where the ranges are too large. Drawbacks of such an approach are that the important information in the adding up constraints (and often the existence of small state-ind ustries) is being ignored, and that industries with interesting agglomerations often end up being dropped.
} 
plants in each of ten employment size ranges. ${ }^{27}$ Subject to disclosure rules, the total number of employees within the plants of a size category is also usually reported. The withholding is somewhat more of a problem here than in the construction of the state employments because it is primarily the shares of the largest plants which are obscured by the nondisclosure rules. For each industry we used the data to estimate a sum of squared plant shares using a two step procedure: employees were first allocated between the classes where data was withheld, and a Herfindahl index was then estimated by a procedure similar to that recommended

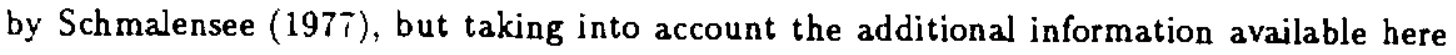
in the form of the category divisions. To get a rough idea of the magnitude of the resulting measurement errors we conducted tests of our algorithm on simulated data. The details of the data construction and of the simulations are reported in Appendix $B$. The simulations suggest that measurement errors are not likely to substantially bias our results. A complete list of our estimated plant Herfindahls is given in Appendix C.

A firm level Herfindahl index, $H_{f}$, was taken directly from the Census of Manufactures' Concentration Ratios in Manufacturing. The data are based on shares of shipments of the top 50 firms rather than on all firms' employment, and are available for 444 of the 459 industries, with the values for the remaining fifteen (highly concentrated) industries with held because of disclosure rules. We drop these industries whenever our analysis uses $H_{f}$. In the restricted sample of 444 industries, the mean of $H_{f}$ is 0.068 and that of $H_{p}$ is 0.025 . It is interesting to note as an aside that following Scherer (1975) one may use the ratio of these two concentration measures for an industry as an estimate of the effective number of plants operated by the large firms. ${ }^{28}$ In doing so, we find a mean across industries of 3.8 plants/firm and a median of 2.7 , figures roughly comparable to those reported by Scherer twenty years ago. The ratio takes on its largest value, 30.1 , in S.I.C. 2813 , industrial gases.

Finally, for our analysis of the geographic scope of concentration we obtained a dataset of 1987 county level employments for 3-digit industries. The dataset had been constructed by filling in County Business Patterns data using an algorithm which consists largely of using mean plant sizes for all nondisclosed employments. ${ }^{29}$ Some comparisons of this data with our primary dataset are given at the end of Appendix A.

\footnotetext{
${ }^{27}$ The ranges are those determined by the lower bounds of $1,5,10,20,50,100,250,500,1000$, and 2500 employees.

2t The estimate is literally valid only if each firm's activities are divided evenly between the same number of plants.

${ }^{29}$ See Gardocki and Baj (1985)
} 


\section{Basic Results on Geographic Concentration}

In this section we describe the patterns of geographic concentration in U.S. manufacturing industries. We begin at the broadest level with a discussion of whether any geographic concentration exists before moving on to discuss a few aspects in a little more detail.

\subsection{Are Industries Geographically Concentrated?}

The single most crucial question one must ask before further studying the geographic concentration of industries is whether geographic concentration really exists. While a number of previous writers have noted that localization appears to be widespread, we present here for the first time formal tests of the more stringent hypothesis that the extent of localization is greater than that which would be expected to arise randomly.

We begin with what is clearly the most compelling application of our simple dartboard model, assuming that the plants in an industry are the business units choosing their locations in an independent random manner. The prediction of the model is that $E(G)=H_{p}$, with the difference between $G$ and $H_{p}$ being heteroskedastic with a variance given in Proposition 2. For the full sample of 459 industries we find that the means of $G$ and $H_{p}$ are 0.77 and 0.28 , respectively. The simple dartboard model predicts that the sample average of the $G$ 's should have a mean of 0.28 and a standard deviation of 0.0005 , so this difference is highly significant indicating that there is excess localization relative to random location choice.

Looking at the industry-by-industry estimates the prevalence of excess localization which previous authors have noted is strikingly confirmed. The level of raw concentration $G$ exceeds that which would be expected to arise randomly in 446 of the 459 industries. ${ }^{30}$ In fact, the flip side of this result - that in only 13 industries are plants more evenly distributed than would be expected at random - is interesting in that it indicates that the need to be near final consumers is rarely an overwhelming force in location decisions.

Before discussing patterns of geographic concentration in more detail, we would like to comment briefly on an alternate application of the dartboard model which might potentially account for higher levels of concentration. Specifically, one could apply the model by assuming instead that the firms in an industry are the business units, with each choosing a common location for all of its plants. While this extreme is plainly counterfactual, it may provide a more reasonable test for the hypothesis that locations are random in some instances. For example, for a number of years Maytag had exactly two plants in which it manufactured washing machines, and both of these were located in Newton, lowa. The

\footnotetext{
${ }^{30}$ The difference between $G$ and $H_{p}$ is larger than twice its standard deviation in 369 of the 446 industries in which the difference is positive, and none of the 13 industries in which the difference is negative.
} 
two location decisions were not independent, and given that the entire industry (SIC 3633) consists of only 18 plants, treating them as independent observations might lead to a misleading conclusion that locations are unlike those expected from independent random dart throws.

Looking first at the overall level of concentration, we note that for the 444 industries for which $H_{f}$ was available the means of $G$ and $H_{f}$ are 0.074 and 0.068 , respectively. While the overall level of concentration appears to be approximately that predicted by the theory, there is a difference between correctly predicting the overall level of concentration and predicting the pattern of concentration across industries. A more demanding test of the firm-random location theory is obtained by estimating the parameters in the regression $G_{i}=\alpha_{0}+\alpha_{1} H_{f i}+\epsilon_{i}$ and testing whether $\alpha_{0}=0$ and $\alpha_{1}=1$. OLS estimates of this equation are given in Table 1. Each of the equalities is rejected individually with a tstatistic of at least 10 , and an $F$-test of the joint hypothesis yields an $F_{2,442}$ statistic of 177.8 , also rejecting strongly. The model thus fails to account for pattern of concentration across industries, which should not be surprising given that we know that multiplant firms do often choose multiple locations. The comparison does provide some intuition for the degree to which manufacturing industries are localized: they are approximately as localized as would be expected if units as large as firms' operations in each industry chose locations at random.

Table 1: Test of the Firm-Random Location Theory

\begin{tabular}{lcc}
\hline \hline \multicolumn{3}{l}{ Equation: $G_{i}=\alpha_{0}+\alpha_{1} H_{f i}+\epsilon_{i}$} \\
Parameter & Coeff. Estimate & Std. Error \\
\hline Constant & $0.047^{*}$ & 0.005 \\
$H_{J}$ & $0.394^{*}$ & 0.057 \\
\hline$R^{2}=0.09$ & \multicolumn{2}{l}{} \\
\hline${ }^{*}$ indicates significance at the $1 \%$ level.
\end{tabular}

\subsection{Levels of Geographic Concentration}

From the previous section we know that the degree of localization in U.S. manufacturing industries is not zero. In this section we try to use our models to get a feel for how much concentration there is. It seems likely that the agglomerative forces reflected in our models will vary greatly from industry to industry. We therefore begin by imposing no structure across industries and simply computing the index $\gamma$ defined by (2) for each of the 4594 - 
digit industries in our sample. ${ }^{31}$ Recall that $\gamma$ can be interpreted either as the probability with which any pair of plants choose their locations jointly or as a measurement of the importance of natural advantage in location choice. A complete list of the $\gamma$ 's we find is contained in Appendix C.

A histogram illustrating the frequency distribution of these $\gamma$ 's is presented in Figure 1. In the figure, each bar represents the number of industries for which $\gamma$ lies in an interval of width 0.01 . The tallest bar is that corresponding to values of $\gamma$ between 0 and 0.01 . The distribution appears to be quite skewed, with a mean of 0.051 and a median of 0.026 . Approximately $43 \%$ of the industries have $\gamma<0.02$, while $26 \%$ have $\gamma>0.05$.

How large are these values? Recall that if an industry has many equal sized plants (so that $I \approx 0$ ), the natural advantage and spillover models both predict that $E(G)=\gamma$. A similar level of concentration would result from completely independent random location decisions by $1 / \gamma$ equal sized plants. Hence, for the 118 industries with $\gamma<0.01$ we can think of agglomerative forces as being sufficiently weak so that if not for the fewness of plants, production would be no more concentrated than if it were scattered at 100 equal sized sites. While there is no justification for any definition of the phrase "not very localized," we feel that it would be an appropriate description of such a pattern, and we apply it both to these and to the other 88 industries with $\gamma<0.02$. At the other extreme, we shall refer to industries with $\gamma>0.05$ as "very localized". This category contains 119 industries.

The reader should keep in mind that if one views locations as being generated by a random process, an individual industry's $\gamma$ is a parameter estimate with a nontrivial standard deviation. To get a feel for the size of this uncertainty in our measurements, we computed standard errors by simulating a special case of our natural advantage model that of Dirichlet-distributed state sizes. ${ }^{32}$ Among industries with $H_{p}<0.02$ the mean of the estimated standard errors is 0.02 . The means for industries with $H_{p}$ in the ranges 0.02 $-0.05,0.05-0.10$, and $0.10-1.0$ are $0.024,0.041$, and 0.072 , respectively.

To provide some intuition for the importance of accounting properiy for random agglomeration when constructing an index of geographic concentration, Table 2 lists the frequency with which $\gamma / G$ falls into a number of intervals, both for all industries and for the subsample of those in the upper quartile of raw geographic concentration. We can think of the fraction as a rough measure of the portion of raw concentration which is legitimately attributable to some form of spillovers/natural advantage rather than to randomness. The table indicates that the two components are comparable in magnitude and that there is

\footnotetext{
${ }^{31}$ Note that we assume here and throughout the rest of the paper that the plants are the buginess units choosing locations.

${ }^{32}$ The computation requires also a more complete specification of the plant size distribution. For this purpose, we took the plant sizes to be those used as an intermediate step to the Herfindabl calculation.
} 
Figure 1: Histogram of $\gamma$

Histogram of Gamma

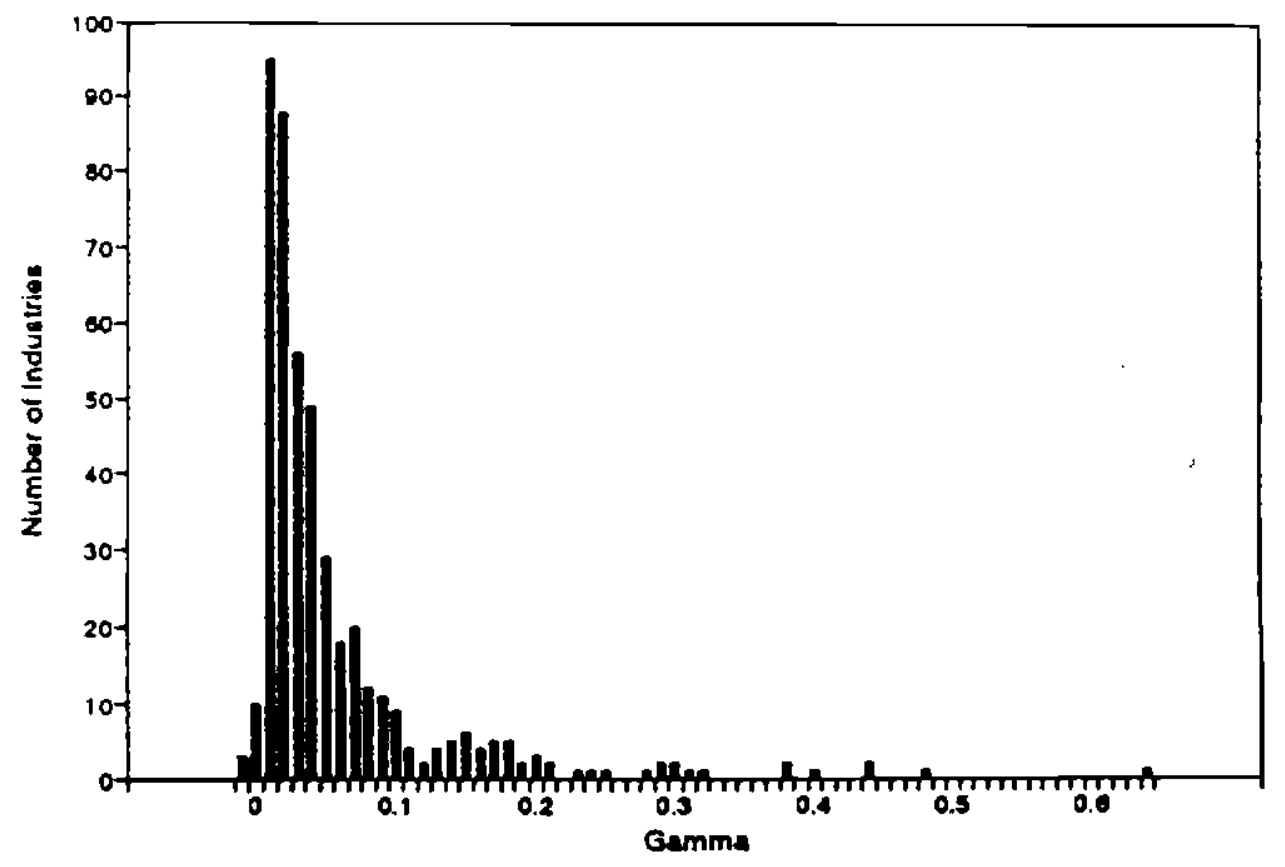


great variation in the mix between them. In roughly one third of the industries (both overall and among the industries with high raw concentration) the fact that plants are discrete units and that some clusters appear at random accounts for at least as large a part of measured raw concentration as do actual agglomerations of plants. Our index may then give a somewhat different picture of geographic concentration than would a discussion of raw concentrations.

Table 2: Raw Concentration Attributable to Spillovers/Comparative Advantage

\begin{tabular}{ccc}
\hline \multicolumn{3}{c}{ Fraction of Industries with $\gamma / G$ in Range. } \\
Range & All Industries & High G Industries \\
\hline Less than 0 & 0.03 & 0.03 \\
$0.00-0.25$ & 0.09 & 0.10 \\
$0.25-0.50$ & 0.22 & 0.16 \\
$0.50-0.75$ & 0.32 & 0.19 \\
$0.75-1.00$ & 0.33 & 0.53 \\
\hline
\end{tabular}

\subsection{Patterns of Concentration}

An attempt to explore formally the industry characteristics which tend to be associated with localization is well beyond the scope of this paper. ${ }^{33}$ We would, however, like to present a few more tables concerning the geographic concentration in different industies.

In Table 3 we summarize the levels of geographic concentration of the 4-digit subindustries of each 2-digit manufacturing industry. For each 2-digit industry, the table lists the fraction of subindustries which fall in the not very localized $(\gamma<0.02)$, intermediate, and very localized $(\gamma>0.05)$ ranges. High levels of geographic concentration are most prevalent in the tobacco, textile, and leather industries and most rare in the paper, rubber and plastics, and fabricated metal products industries.

In hopes that the forces affecting geographic concentration might be clearest at the extremes, Table 4 lists the 15 most and the 15 least localized industries in terms of the index $\gamma$. As Krugman (1991a) has previously noted, there is no obvious single factor accounting for extreme concentration. The most concentrated industry, furs, is probably explained both by the local transfer of knowledge from one generation to the next, and as a response to buyers' search costs. Furs also have an unusually high ratio of value to weight. The next most concentrated, wine, may be largely attributable to the natural

\footnotetext{
${ }^{33}$ For interesting work on this topic see Henderson (1988) and Enright (1990).
} 
Table 3: Concentration by 2-digit Category

\begin{tabular}{|c|c|c|c|c|}
\hline \multirow[b]{2}{*}{ 2-digit industry } & \multirow{2}{*}{$\begin{array}{l}\text { \# of 4-digit } \\
\text { subindustries }\end{array}$} & \multicolumn{3}{|c|}{ Percent of 4-digit industries with } \\
\hline & & $\gamma<0.02$ & $\gamma \in[0.02,0.05]$ & $\gamma>0.05$ \\
\hline 20. Food and kindred products & 49 & 47 & 18 & 35 \\
\hline 21. Tobacco products & 4 & 0 & 0 & 100 \\
\hline 22. Textile mill products & 23 & 9 & 13 & 78 \\
\hline 23. Apparel and other textile products & 31 & 13 & 42 & 45 \\
\hline 24. Lumber and wood products & 17 & 29 & 47 & 24 \\
\hline 25. Furniture and fixtures & 13 & 69 & 8 & 23 \\
\hline 26. Paper and allied products & 17 & 53 & 47 & 0 \\
\hline 27. Printing and publishing & 14 & 71 & 14 & 14 \\
\hline 28. Chemicals and allied products & 31 & 38 & 24 & 38 \\
\hline 29. Petroleum and coal products & 5 & 60 & 0 & 40 \\
\hline 30. Rubber and misc. plastics & 15 & 73 & 27 & 0 \\
\hline 31. Leather and leather products & 11 & 0 & 36 & 64 \\
\hline 32. Stone, clay, and glass products & 26 & 58 & 27 & 15 \\
\hline 33. Primary metal industries & 26 & 39 & 35 & 27 \\
\hline 34. Fabricated metal products & 38 & 61 & 32 & 8 \\
\hline 35. Industrial machinery and equipment & 51 & 49 & 26 & 26 \\
\hline 36. Electronjc and other electric equip. & 37 & 41 & 46 & 14 \\
\hline 37. Transportation equipment & 18 & 28 & 33 & 39 \\
\hline 38. Instruments and related products & 17 & 47 & 41 & 11 \\
\hline 39. Miscellaneous manufacturing ind. & 18 & 44 & 22 & 33 \\
\hline
\end{tabular}


advantage of California in growing grapes. The concentration of oilfield machinery (in the Houston/Galveston area) may be partially attributable to the location of oil production.

The list of the 15 least concentrated industries is also something of a mixed bag. The industries certainly do not stand out as being those in which spreading out to be close to final consumers is important, and the list contains several industries, e.g. vacuum cleaners and small arms ammunition, where raw concentration is substantial, but employment turns out to be concentrated in a few very large (randomly scattered) plants. ${ }^{34}$

\section{Scope of Geographic Concentration}

In this section we examine two different aspects of the scope of geographic concentration. First. we discuss the scope in the sense of industrial definition, i.e. whether concentration is principally a phenomenon which exists at the level of individual industries or whether it is characteristic of broad industry classes as well. Next, we discuss the geographic scope of concentration, comparing data at the county, state, and regional levels.

\subsection{Industry Definition}

Table 5 provides a simple look at the concentration of 2-, 3-, and 4-digit industries. While raw geographic concentration increases steadily as we move to finer industry definitions, the increase in $\gamma$ appears to come more abruptly as we move from the 2-digit to the 3-digit level. This naturally raises two questions of scope. Is there any correlation in the location decisions of firms which share only a two digit industry class, or is the concentration of 2-digit industries entirely a consequence of the localization of its 3-digit subindustries? Are location decisions influenced as strongly by the locations of plants belonging to different 4digit industries within the same 3-digit class as they are by the locations of plants belonging to their own 4-digit industry? In this section, we develop a framework for addressing such questions and apply it to our data.

Consider an industry with $r$ subindustries having shares $w_{1}, w_{2}, \ldots, w_{r}$ of the overall industry employment. Write $H^{j}$ for the plant Herfindahl of the $j^{\text {th }}$ subindustry, and $H=$ $\sum_{j=1}^{r} w_{j}^{2} H^{j}$ for the plant Herfindahl of the broader industry. Suppose that plants choose their locations in a manner which is nearly identical to that of our spillover model, but that the probability of any pair of darts being welded together (i.e. that a crucial spillover exists between the firms they represent) being $\gamma_{j}$ if both darts correspond to plants within the

\footnotetext{
${ }^{34}$ In interpreting these Jatter cases the reader stould keep in mind that the errors in measuring $r$ include both the inherent uncertainty of analyzing random dart throws and errors in filling in Census nondisclosures. Each of these components is larger when $H_{p}$ is larger, so the liat may contan many indnstries with large $H_{p}$ simply because this is where we have made the largest errora in measurement.
} 
Table 4: Most and Least Localized Industries

\begin{tabular}{|c|c|c|c|}
\hline \multicolumn{4}{|c|}{15 Most Localized Industries } \\
\hline 4-digit ind ustry & $H_{p}$ & $G$ & $\gamma$ \\
\hline 2371. Fur Goods & 0.007 & 0.63 & 0.63 \\
\hline 2084. Wines, Brandy, Brandy Spirits & 0.041 & 0.50 & 0.48 \\
\hline 2252. Hosiery, n.e.c. & 0.008 & 0.44 & 0.44 \\
\hline 3533. Oil and Gas Field Machinery & 0.015 & 0.44 & 0.43 \\
\hline 2251. Women's Hosiery & 0.028 & 0.42 & 0.40 \\
\hline 2273. Carpets and Rugs & 0.013 & 0.39 & 0.38 \\
\hline 2429. Special Product Sawmills, n.e.c. & 0.009 & 0.38 & 0.37 \\
\hline 3961. Costume Jewelry & 0.017 & 0.33 & 0.32 \\
\hline 2895. Carbon Black & 0.054 & 0.34 & 0.30 \\
\hline 3915. Jewelers' Materials, Lapidary & 0.025 & 0.32 & 0.30 \\
\hline 2874. Phosphatic Fertilizers & 0.066 & 0.34 & 0.29 \\
\hline 2061. Raw Cane Sugar & 0.038 & 0.32 & 0.29 \\
\hline 2281. Yarn Mills, Except Wool & 0.005 & 0.29 & 0.28 \\
\hline 2034. Dehydrated Fruits, Veg's, Soups & 0.030 & 0.30 & 0.28 \\
\hline 3761. Guided Missiles, Space Vehicles & 0.046 & 0.28 & 0.25 \\
\hline
\end{tabular}

15 Least Localized Industries

\begin{tabular}{lccc} 
4-digit industry & $H_{p}$ & $G$ & $\gamma$ \\
\hline 3021. Rubber and Plastics Footwear & 0.06 & 0.05 & -0.013 \\
2032. Canned Specialties & 0.03 & 0.02 & -0.012 \\
2082. Malt Beverages & 0.04 & 0.03 & -0.010 \\
3635. Household Vacuum Cleaners & 0.18 & 0.18 & -0.009 \\
3652. Prerecorded Records and Tapes & 0.04 & 0.03 & -0.008 \\
3482. Small Arms Ammunition & 0.18 & 0.18 & -0.004 \\
3324. Steel Investment Foundries & 0.04 & 0.04 & -0.003 \\
3534. Elevators and Moving Stairways & 0.03 & 0.03 & -0.001 \\
2052. Cookies and Crackers & 0.03 & 0.03 & -0.0009 \\
2098. Macaroni and Spaghetti & 0.03 & 0.03 & -0.0008 \\
3262. Vitreous China Table, Kitchenware & 0.13 & 0.13 & -0.0006 \\
2035. Pickles, Sauces, Salad Dressings & 0.01 & 0.01 & -0.0003 \\
3821. Laboratory Apparatus and Furniture & 0.02 & 0.02 & -0.0002 \\
2062. Cane Sugar Refining & 0.11 & 0.11 & 0.0002 \\
3433. Heating Equipment except Electric & 0.008 & 0.009 & 0.0002 \\
\hline
\end{tabular}


Table 5: Concentration and Industry Definition

\begin{tabular}{cccc}
\hline & \multicolumn{3}{c}{ Industry means } \\
Industry Definition & $H_{p}$ & $G$ & $\gamma$ \\
\hline 2-digit & 0.007 & 0.032 & 0.026 \\
3-digit & 0.014 & 0.058 & 0.045 \\
4 digit & 0.028 & 0.077 & 0.051 \\
\hline
\end{tabular}

$j^{\text {th }}$ subindustry and $\gamma_{0}$ otherwise. We will assume that $\gamma_{0} \leq \operatorname{Min}_{j=1 . . . r} \gamma_{j}$, so that spillovers are always more powerful (in expectation) between plants which are more similar. ${ }^{35}$

Again writing $G$ for the raw geographic concentration of the broader industry we have Proposition 6 In the model above,

$$
E(G)=H+\gamma_{0}\left(1-\sum_{j=1}^{r} w_{j}^{2}\right)+\sum_{j=1}^{r} \gamma_{j} w_{j}^{2}\left(1-H^{j}\right) .
$$

\section{$\underline{\text { Proof }}$}

Write $n_{j}$ for the number of business units in the $j^{\text {th }}$ subindustry and $z_{j 1}, \ldots, z_{j n_{j}}$ for the sizes of plants in that subindustry. Writing $u_{j} \ell_{i}$ for the Bernoulli random variable indicating whether the $\ell^{\text {th }}$ plant in subindustry $j$ locates in area $i$, the assumption on welding implies

$$
\operatorname{Corr}\left(u_{j \ell_{i}}, u_{j^{\prime} \ell_{i}}\right)= \begin{cases}\gamma_{j} & \text { if } j=j^{\prime} \text { and } \ell \neq \ell^{\prime} \\ \gamma_{0} & \text { if } j \neq j^{\prime}\end{cases}
$$

We then have

$$
\begin{aligned}
& \left(1-\sum_{i} x_{i}^{2}\right) E(G)=\sum_{i} \operatorname{Var}\left(s_{i}\right) \\
& =\sum_{i}\left[\sum_{j, \ell} z_{j \ell}^{2} \operatorname{Var}\left(u_{j \ell i}\right)+\sum_{j \ell, \ell^{\prime}, \ell \neq \ell^{\prime}} z_{j \ell} z_{j \ell^{\prime}} \operatorname{Cov}\left(u_{j \ell i}, u_{j \ell^{\prime} i}\right)\right. \\
& \left.+\sum_{j, j^{\prime}, \ell, \ell^{\prime}, j \neq j^{\prime}} z_{j \ell} z_{j^{\prime} \ell^{\prime}} \operatorname{Cov}\left(u_{j \ell^{\prime}}, u_{j^{\prime} \ell^{\prime} i}\right)\right] \\
& =\left(\sum_{i} x_{i}\left(1-x_{i}\right)\right)\left[\sum_{j, \ell} z_{j \ell}^{2}+\sum_{j \ell, \ell^{\prime}, \ell \neq \ell^{\prime}} z_{j \ell} z_{j \ell^{\prime}} \gamma_{j}+\sum_{j, j^{\prime}, \ell \ell^{\prime}, j \neq j^{\prime}} z_{j \ell} z_{j^{\prime} \ell^{\prime}} \gamma_{0}\right]
\end{aligned}
$$

\footnotetext{
${ }^{3 s}$ We require also that the welding relation is again gymmetric and transitive. The assumplion that

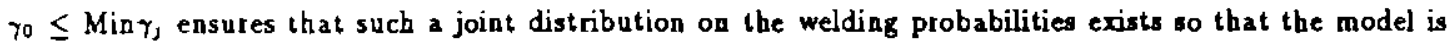
well defined.
} 


$$
\begin{aligned}
E(G) & =H+\sum_{j} \gamma_{j}\left(w_{j}^{2}-\sum_{\ell} z_{j \ell}^{2}\right)+\gamma_{0}\left(1-\sum_{j} w_{j}^{2}\right) \\
& =H+\gamma_{0}\left(1-\sum_{j} w_{j}^{2}\right)+\sum_{j} \gamma_{j} w_{j}^{2}\left(1-H^{j}\right) .
\end{aligned}
$$

QED.

Given data on state-industry employments for an industry and for each of its subindustries, raw geographic concentrations may be computed both for the larger industry and for the subindustries. Write $G_{j}$ for the raw concentration in the $j^{\text {th }}$ subindustry and $\dot{\gamma}_{j}$ for $\frac{G_{2}-H}{1-H}$. An unbiased estimate of the degree of intersubindustry spillovers may then be obtained from the raw concentrations by setting

$$
\tilde{\gamma}_{0}=\frac{G-H-\sum_{j=1}^{r} \hat{\gamma}_{j} w_{j}^{2}\left(1-H^{j}\right)}{1-\sum_{j=1}^{r} w_{j}^{2}} .
$$

To discuss the degree to which spillovers are general, we define a new measure $\lambda$ by

$$
\lambda=\frac{\hat{\gamma_{0}}}{\sum_{j} w_{j} \hat{\gamma}_{j}} .
$$

Note that this measure should be zero if there are no spillovers between plants in different subindustries and one if spillovers are equally strong regardless of the subindustry to which plants in the same broad industry belong. ${ }^{36}$

There are 97 3-digit industires with more than one 4-digit subindustry. A histogram for $\lambda$ on these three-digit industries is given in Figure 2. The values of $\lambda$ are fairly evenly spread between 0 and 0.8 , indicating that there certainly is some clustering of similar 4-digit industries. In answer to our introductory question, however, it appears that spillovers are nearly as strong across 4-digit industries in the same 3-digit industry as within the 4-digit industries themselves only in about $20 \%$ of the cases.

Moving on to yet broader industry classes, Table 6 reports the results of the identical calculation using the 3-digit subindustries of each 2-digit industry. The mean value of $\lambda$ across 2-digit industries is 0.29 . There is great variation across industries. In four cases (furniture, industrial machinery, electronic and electric equipment, and transportation equipment) the data indicate that there is no concentration at all at the 2 -digit level. On the other hand, there is substantial concentration of the 3-digit industries within the 2-digit tobacco, textile, and lumber industries.

We should note while we have tended to use the word "spillovers" in this section, several factors may explain the results. Technology or knowledge spillovers are one possibility, but

\footnotetext{
${ }^{36}$ Of course, $\lambda$ is a random variable so these statements apply likerally only to $\frac{z_{0}}{\sum_{j}{ }_{j j}}$. Note also that $\lambda$ is not an unbiased estimale of this expression. An earlier version of this paper defined $\lambda$ by a linear interpolation which in practice yields values alrost identical to those we report here.
} 
Figure 2: Extent of Spillovers between 4-digit Industries

\section{Histogram of Lambda \\ 3-Digit Industries}

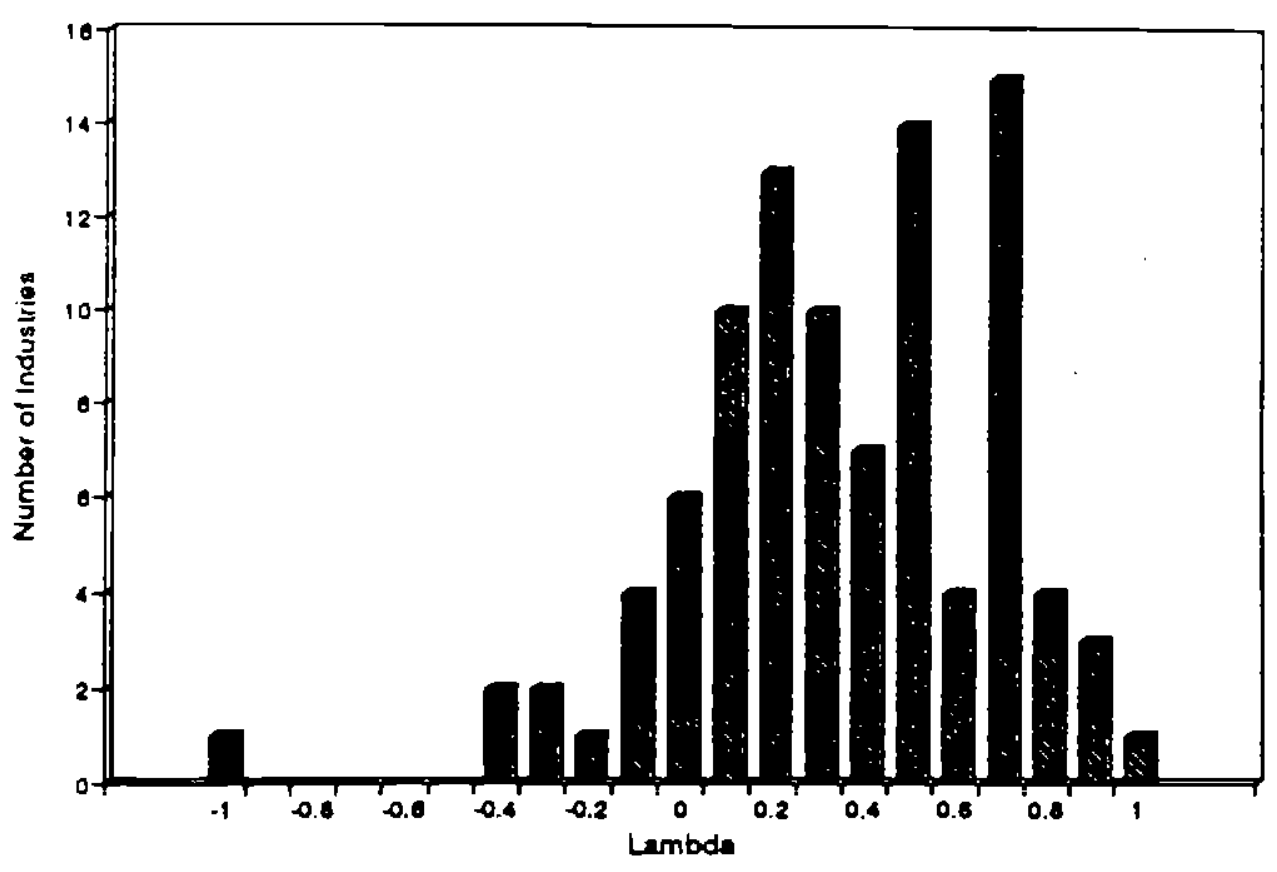


spatially correlated natural advantages or other "spillovers" like minimizing transportation costs given intersubindustry trade could also account for positive values of $\lambda$. While a more detailed analysis is clearly called for, the list of 2-digit industries where $\lambda$ is largest suggests that we may be detecting in large part that the "natural advantages" which are important to the subindustries are similar.

Table 6: Extent of Spillovers between 3-digit Industries

\begin{tabular}{lrrlrr}
\hline \hline 2-digit industry & $\dot{\gamma}_{0}$ & $\lambda$ & 2-digit industry & $\hat{\gamma}_{0}$ & $\lambda$ \\
\hline Food and kindred products & 0.002 & 0.14 & Rubber and misc. plastics & 0.003 & 0.38 \\
Tobacco products & 0.151 & 0.88 & Leather and leather products & 0.017 & 0.31 \\
Textile mill products & 0.115 & 0.61 & Stone, clay, and glass products & 0.002 & 0.20 \\
Apparel and other textiles & 0.010 & 0.29 & Primary metal industries & 0.012 & 0.41 \\
Lumber and wood products & 0.016 & 0.63 & Fabricated metal products & 0.003 & 0.22 \\
Furniture and fixtures & 0.001 & 0.02 & Industrial machinery and equip. & 0.000 & 0.00 \\
Paper and allied products & 0.005 & 0.31 & Electronic \& other electric equip. & 0.000 & 0.02 \\
Printing and publishing & 0.005 & 0.48 & Transportation equipment & -0.001 & -0.08 \\
Chemicals and allied products & 0.007 & 0.25 & Instruments and related products & 0.013 & 0.36 \\
Petroleum and coal products & 0.007 & 0.12 & Miscellaneous manufacturing & 0.011 & 0.34 \\
\hline
\end{tabular}

\subsection{Geographic Scope of Concentration}

In Section 3, we noted that the $\gamma$ 's estimated from county-, state-, or region-level data should be identical (in expectation) provided the scope of spillovers is such that advantages are gained only if firms choose identical locations. If on the other hand the effect of spillovers (or the spatial correlation of natural advantage) is smoothly declining with distance, then those $\gamma$ 's will reflect the excess probability with which pairs of firms tend to locate in the same county, state, and region, respectively. To investigate the geographic scope of spillovers we estimated $\gamma$ 's from our county/3-digit dataset using counties, states, and the nine census regions as the units of observation.

Figure 3 presents histograms of the $\gamma$ 's estimated from the three levels of data. Comparing first the county-and state-level estimates note that substantially more concentration is apparent at the state level. The median $\gamma$ 's at the two levels are 0.005 and 0.023 , with the median of the ratio between them being 0.25 , so that typically the effect of spillovers is such that about one fourth of the excess tendency of plants to locate in the same state involves 
Figure 3: Concentration at the County, State, and Regional Level

County-Lovei Gammas
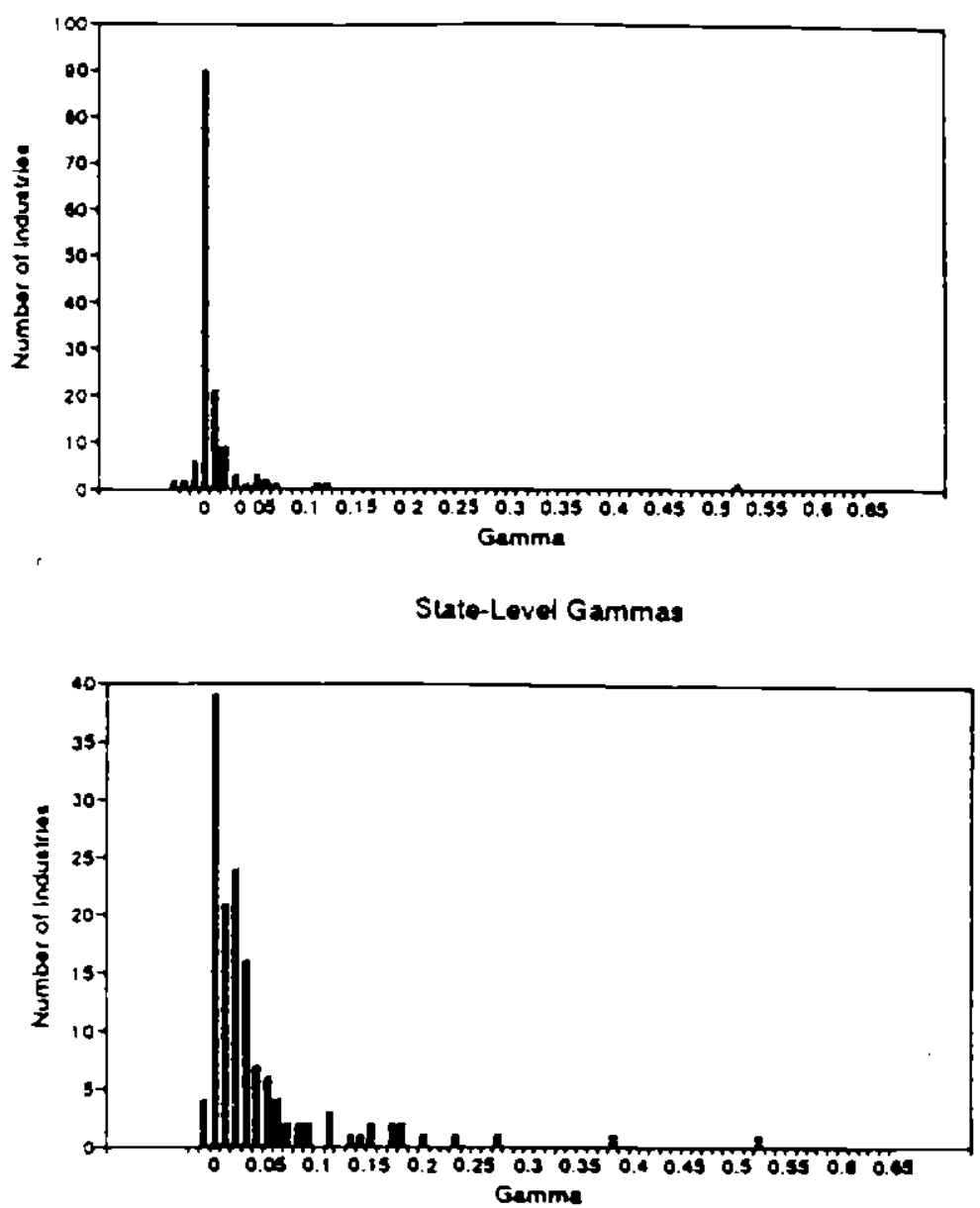

Region-Lovel Gammas

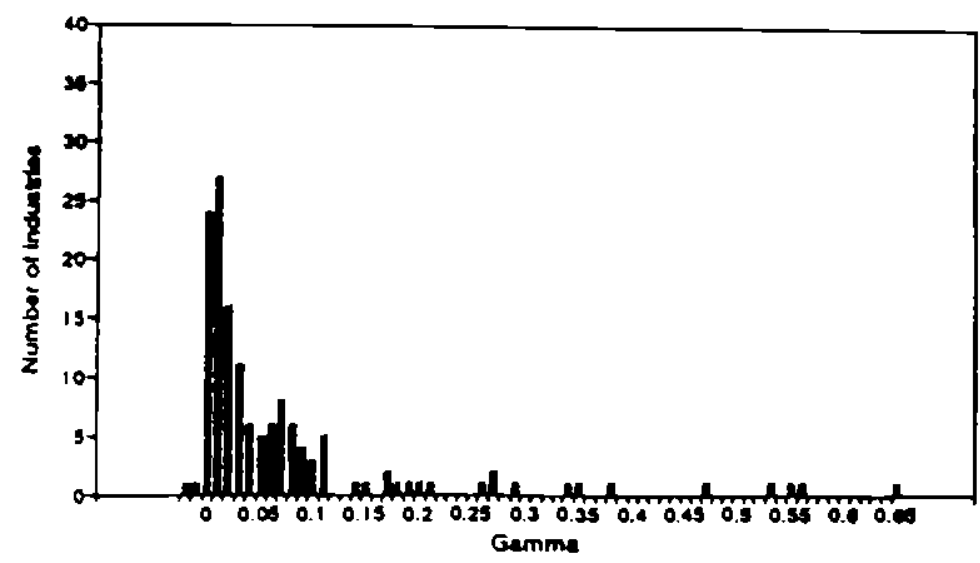


plants locating in the same county. We draw two conclusions. First, given that states have many more than 4 counties, spillovers appear to have a stronger effect at very small distances. Second, spillovers are still quite substantial at a range beyond that of counties. In only a few cases do spillovers appear both to be substantial and limited in scope to the county level. ${ }^{3 T}$ The rubber and plastics footwear industry seems to be the unique example where concentration is substantially greater at the county level than at the state level, i.e. where tightly grouped clusters of plants are spread (excessively) evenly across the states as if to minimize transportation costs.

Measured levels of state and regional concentration are more similar, although the regional data shows a much thicker tail of very concentrated industries. (The mean $\gamma$ 's are 0.044 and 0.078 .) The general pattern of slightly more than half of the tendency of firms to locate in the same region being accounted for by the tendency to locate in the same state appears to hold equally well for industries which are very unconcentrated and very concentrated at the state level, although there is considerable variation about this norm. ${ }^{38}$

\section{Geographic Concentration within the Firm}

In this section we investigate the tendency to locate together of plants belonging to the same firm. The issue is interesting not only in its own right, but also in that such a tendency might account for a significant portion of the localization we have identified.

To analyze the potential for measuring agglomeration within the firm, we consider an industry consisting of $r$ firms with shares $w_{1}, w_{2}, \ldots, w_{r}$ of the industry's employment. Suppose that firm $j$ consists of $n_{j}$ plants having shares $z_{j 1}, \ldots, z_{j n_{j}}$ of the industry's employment. Assume that the location choices of the plants are again made as in our spillover model with the probability of a pair of darts being welded being equal to $\gamma_{0}$ if they correspond to plants in different firms and $\gamma_{1}>\gamma_{0}$ if they belong to the same firm. The model is thus a special case of the model of Section 6.1 with the firms analogous to subindustries and the expected degree of spillovers within each firm assumed to be identical. A direct corollary of Proposition 6 is

Proposition 7 In the model above,

$$
E(G)=H_{p}+\gamma_{0}\left(1-H_{J}\right)+\gamma_{1}\left(H_{J}-H_{p}\right) .
$$

\footnotetext{
${ }^{37}$ The most notable cases are fur goods, building paper and board mills, and periodicals.

${ }^{34}$ Ind untries notable for unusually high (relative) regional concentration include ordance and accessories, nonferroua foundries, and cigarettes. Industries in which state-level clusters are unusually dispersed include photographic equipment and supplies, radio and television receiving equipment, and periodicals.
} 
In trying to apply the prediction of this model to recover $\gamma_{1}$, a great obstacle arises state-firm employments are much harder to find than state-industry employments. As a result, we cannot separately estimate $\gamma_{0}$ and $\gamma_{1}$ for a single industry. What we try to do instead is to identify average values of $\gamma_{0}$ and $\gamma_{1}$ using cross-industry variation. Specifically, we note that if one makes the heroic assumption that the parameters $\gamma_{0 i}$ and $\gamma_{1 i}$ for industry $i$ are random variables whose conditional means are independent of $H_{p i}$ and $H_{f i}$, then the coefficients $\dot{\alpha_{0}}$ and $\dot{\alpha_{1}}$ from the OLS regression

$$
G_{i}-H_{p i}=\alpha_{0}\left(1-H_{p i}\right)+\alpha_{1}\left(H_{f i}-H_{p i}\right)+\epsilon_{i}
$$

are consistent for $E\left(\gamma_{0}\right)$, and $E\left(\gamma_{1}\right)$.

We estimated the regression above for our sample of 4444 -digit industries. The parameter estimates are $\hat{\alpha_{0}}$ and $\hat{\alpha_{1}}$ are 0.046 (s.e. 0.005 ) and 0.068 (s.e. 0.067 ), respectively. While the first coefficient estimate is highly significant, the second is quite imprecise. Hence, while the point estimate is that plants belonging to the same firm are slightly more agglomerated than other plants in the same industry, we can not rule out a substantially higher level of intrafirm agglomeration. Given that the mean of $H_{f}-H_{p}$ is only 0.04 , we can say fairly confidently that only a very small portion of total geographic concentration is attributable to intrafirm agglomerations.

As a simple specification test for this model, we estimated also the unconstrained regression

$$
G_{i}=\beta_{0}+\beta_{1} H_{J i}+\beta_{2} H_{p i}+\epsilon_{i}
$$

and performed a Wald test of the restriction $\beta_{0}+\beta_{1}+\beta_{2}=1$. The test does reject the specification at the $5 \%$ level, although we note that the test would no longer reject if we made the minor bias correction suggested by Appendix B. While we believe the results of this section are of interest, we thus admit that they clearly should be interpreted with some caution.

\section{Conclusion}

In this paper we have developed a new framework for the analysis of geographic concentration based on a dart throwing metaphor. Using a series of very simple models, we obtain characterizations of both "random" agglomeration and of agglomeration caused by spillovers and natural advantage. Our most important theoretical result is that it is possible to control for industry characteristics in a fairly robust manner when measuring geographic concentration. This leads us to propose two new "natural" indices, $\gamma$ and $\lambda$, to measure the localization of industries and the relative strength of cross-industry agglomerations. 
The empirical work of this paper is largely descriptive. Besides reaffiming that localization is ubiquitous, we have tried to develop rough sketches of the variation of localization across industries, the geographic and industry levels at which it is most prominent, and its relationship to the structure of multiplant firms.

The existence of geographic concentration has attracted the attention of researchers in many fields and many potential explanations have been proposed. In the future, we hope that our measurement techniques will prove useful both in descriptive work on the nature of geographic concentration and in attempts to use the facts uncovered to assess the relative importance of various agglomerative forces. 


\section{References}

Carlton, Dennis (1983): "The Location and Employment Decisions of New Firms: An Econometric Model with Discrete and Continuous Exogenous Variables," Review of Economics and Statistics, 65, 440-449.

Creamer, Daniel (1943): "Shifts of Manufacturing Industries," in Industrial Location and Natural Resources. Washington, DC: US Government Printing Office.

Enright, Michael (1990): Geographic Concentration and Industrial Organization. Ph.D. thesis, Harvard University.

Florence, P. Sargant (1948): Investment, Location and Size of Plant. London: Cambridge University Press.

Fuchs, Victor (1957): The Economics of the Fur Industry. New York: Columbia University Press.

Fuchs, Victor (1962): Changes in the Location of Manufacturing in the US Since 1929. New Haven: Yale University Press.

Gardocki, Bernard C., Jr. and Baj, John (1985): "Methodology for Estimating Nondisclosure in County Business Patterns Data," Mimeo.

Glaeser, Edward L., Kallal, Hedi D., Scheinkman, Jose, and Shleifer, Andrei (1992): "Growth in Cities," Journal of Political Economy, 100, 1126-1152.

Henderson, J. Vernon (1988): Urban Development: Theory, Fact and Illusion. New York: Oxford University Press.

Hoover, E.M. (1948): The Location of Economic Activity. New York: McGraw Hill.

Jaffe, Adam, Trajtenberg, Manuel and Henderson, Rebecca (1993): "Geographic Localization of Knowledge Spillovers as Evidenced by Patent Citations," Quarterly Journal of Economics, 108, 577-598.

Krugman, Paul (1991a): Geography and Trade. Cambridge, Mass: MIT Press. 
Krugman, Paul (1991b): "Increasing Returns and Economic Geography," Journal of Political Economy, 99, 483-499.

McFadden, Daniel (1974): "Conditional Logit Analysis of Qualitative Choice Behavior," in P. Zarembka, ed., Fronteirs in Eoconometrics. New Yourk: Academic Press, 1974, pp. $105-42$.

Porter, Michael E. (1990): The Competitive Advantage of Nations. New York: The Free Press.

Scherer, F. Michael. et al. (1975): The Economics of Multi-plant Operation: an International Comparisons Study. Cambridge, Mass: Harvard University Press.

Schmalensee, Richard (1977): "Using the H-index of Concentration with Published Data," Review of Economics and Statistics, 59, 186-193. 


\section{Appendix A}

This appendix describes the process by which state-industry employment figures were constructed. The 1987 Census of Manufactures reports the employment or a range of employments for all state-industries with at least 150 employees. Table 7 indicates the number of these state-industries for which data is categorized, the number of these which are topcoded at $\mathbf{2 5 0 0}$ or more employees, and the average across industries of the fraction of employees whose state cannot be determined simply by assigning each state its minimum possible employment.

Table 7: Extent of Withheld Data

\begin{tabular}{lrrr}
\hline \hline & \multicolumn{3}{c}{ Industry Definition } \\
& 2-digit & 3-digit & 4-digit \\
\# Industries & 21 & 141 & 460 \\
\# Cells with Ranges & 153 & 1776 & 5700 \\
\# Topcodes & 46 & 268 & 487 \\
Avg. Employment Fraction & 0.02 & 0.11 & 0.20 \\
\hline
\end{tabular}

Before beginning to fill in the data, we first adjust the upper or lower bounds on any 2or 3-digit state industry for which a sharper bound can be obtained by summing the upper or lower bounds of the subindustries which comprise it. This reduces the number of 2-and 3 -digit state industries without upper bounds to 13 and 157 , respectively. In addition, a total of 82 and 680 bounds are tightened on cells where a non-topcoded range had been given.

The filling process begins with the $21 \times 51$ matrix of 2-digit data. First, a rough estimate of the total employment in cells which are reported as zero is made for each state and for each industry. The estimate is simply 35 times the number of missing firms with 20 or more employess plus 6 times the number of missing firms with fewer than 20 employees, provided that this total is less than 150 times the number of empty cells in the appropriate row or column. (Each of these estimates is less than 600 employees).

The main part of the algorithm assigns values within the given range to each cell, trying to do so in a manner that makes the sums of the rows and columns as close as possible to those indicated by the reported totals for employment in each industry and manufacturing employment in each state. While this could be treated as a large optimization problem with a number of variables equal to the number of categorized state-industry employments, this approach was deemed intractable and instead an admittedly ad hoc procedure was used to 
sequentially fill in cells. Essentially, the procedure repeatedly looks at the matrix of data, identifies the categorized cells for which there is the least uncertainty as to employment, fills in employment of those cells, and again looks at the matrix in which the filled in numbers are accepted as fact.

The process of identifying which cells to fill in follows a set of priorities. First, if there are any rows or columns for which all categorized cells must be set to the minimum or maximum to satisfy adding up constraints those cells are chosen. Next, the algorithm looks for rows or columns in which only a single element is unknown. If all rows and columns have multiple unknown cells, the algorithm selects the row or column in which there is the least variance possible within the unknown ranges. The manner in which this is done usually results in topcodes not being filled in until virtually all active rows and columns contain a topcode, and rows/columns with multiple topcodes not being filled until there are no rows/columns with a single topcode remaining. When filling cells in a row with multiple unknown elements, the algorithm looks at the departures from expected employment in the row and column of each unknown cell and adjusts the cells in a direction calculated loosely on the analogy of calculating conditional means of normal random variables. The amount by which a cell is adjusted is limited by the constraint that its row/column must be able to sum as well.

After filling the 2-digit data, the process is repeated on the 3-and 4-digit data, the only difference being that instead of using the constraint that the state-industry employments should add up to the state total manufacturing employment we use the set of constraints dictated, for example, by employment within each state in the 3-digit subindustries of a 2-digit industry adding up to the employment in that state in the 2-digit industry.

In addition, the previously estimated state and industry total employments in states whose employments are reported as zero are allocated across state-industries by an algorith$m$ identical to that described above. In the 4-digit data, these rounded-to-zero employments are occasionally a nontrivial fraction of the total employment in an idustry.

While there is no way to tell that this algorithm is doing well, it is at least possible to tell that it is doing badly to the extent that the algorithm is unable to make the state or industry totals add up (although due to rounding errors totals are off by up to 400 employees in industries where no data is withheld). Of the 21 2-digit industries, the maximum error in the adding up constraints is 508 employees with all other industries within 400 . In the 3-digit industries and 4-digit industries there are two and six industries where the error is greater than 400, with two 4-digit industries having errors greater than 1000 employees, the maximum being 2010 (although these two are very big industries). The average error in the state adding up constraints are 31,177 , and 558 at the 2-, 3- and 4-digit level. In all but one of the 2-digit industries and in all but 6 of the 3-digit industries it was never 
necessary to fill in multiple topcodes at the same time.

We would have liked to simulate a data withholding process to provide rough estimates of the bias and variance of measurement error on the raw geographic concentration measure $G$ induced by our data filling. However, the Census's withholding process is not sufficienty transparent that we felt confident that we could reasonably simulate it. Absent that, we present here a small test of the accuracy of our procedure based on data obtained separately from the County Business Patterns for the area where our procedure is most suspect, filling in topcodes in the 4-digit data.

Data was available from County Business Patterns on state-industry employment for 171 of the 4874 -digit state-industries where employment was topcoded at 2500 or more. The CBP's sample differs somewhat from the Census of Manufactures, and as a result the CBP reported employment is below 2500 in 30 of these state-industries. We dropped these state-industries from our test. (We chose not to use CBP data as an input to our algorithm precisely because it is often incompatible with range and adding up constraints in the Census of Manufactures data.) Of the remaining 141 state-industries, four have very large employments and in each case our data fit extremely well, giving our estimates a misleadingly high 0.98 correlation with the CBP data. Across the remaining 137 stateindustries the mean and standard deviation of employment are virtually identical in our data and in the CBP data and the correlation between the two is 0.74 . (The means are 5329 and 5304, the standard deviations 3451 and 3306.) For comparison, if the Census of Manufactures had reported ranges for this data using the CBP ranges (2500-4999, 5000 10000 , and 10000-20000) and we had constructed estimates simply by filling in the mean of the appropriate range, the correlation coefficient would be higher $(0.93)$, but the sample means and variance would be much further from those of the CBP data. (The mean would be 5939 , and the standard deviation 4314 ).

While the results above suggest that our procedure has some accuracy in filling, the most important question is clearly what implications errors in assigning state-employments have on the computation of $G$. Even a procedure which is quite inaccurate might yield reasonable estimates of $G$ if it simply assigns clusters of employment to the wrong states. As a rough estimate of the effect of that our filling in of topcodes has on the computation of $G$, we constructed a measure of $G_{c b p}$ by substituting the CBP employment totals for our filled in employment totals for all topcoded cells in the 61 industries where the CBP data allowed all topcodes to be filled in (and where there was at least one topcode). For this purpose we took the CBP data to report an employment of 2500 whenever it actually reported a smaller number. Comparing our previously estimated $G$ with the value $G_{c b p}$, we find that the means are 0.054 and 0.050 , with correlation of 0.96 . The absolute value of the difference between the two has a median of 0.0015 , with the value being larger than 
0.005 in 11 of the 61 industries. While this suggests that our filling of topcodes does not induce significant bias or large measurement errors, we should point out that the industries in which this test was performed may have been among the easier industries with topcodes to fill because they tended to have fewer topcodes than the average industry with at least one topcode ( 1.5 vs. 2.5 ). On the other hand, the majority of 4-digit industries have no topcoded cells to begin with. Also, while we the filled topcodes would appear to be the greatest potential problem with our algorithm, this test says nothing about biases due to the filling of nontopcoded ranges and of state-industry employments of less than 150 .

For another look at the sensitivity of measured levels of concentration to the way in which we filled in the data, we compared the values of $G$ obtained from a state/3-digit industry calculations with our standard dataset and with state totals from our county-level dataset. (Recall that this latter dataset had been constructed entirely from CBP data using mean establishment sizes to fill in missing values.) Because the latter dataset is not based on the 1987 SIC revision, the comparisons below involve only the 96 SIC codes whose definitions were unchanged. The values of $G$ from the two data sources differ (in absolute value) by less than 0.005 in 59 of the 96 industries. The difference is between 0.01 and 0.02 in 14 industries, and greater than 0.02 in eight. In several of these cases, however, the values of $G$ are quite large so that we may regard the two datasets as giving roughly similar measurements. The differences are both larger than 0.015 and larger than $20 \%$ of the larger $G$ for only eight SIC codes: $213,281,302,315,321,375,386$, and 387 . The data for these industries should perhaps be treated with some caution. 


\section{Appendix B}

This appendix discusses the manner in which the variable $H_{p}$ was constructed from the Census data and the potential implications for our measurements of geographic concentrar tion. Given that a significant amount of information about the distribution of plant shares within each industry is available, we have chosen to construct $H_{p}$ by a procedure which is much more akin to filling in data than to imposing any distributional assumptions and estimating parameters, and which therefore will admittedly be ad hoc. The algorithm has two main steps: the first consisting of allocating employees across size classes to obtain a regular data structure, and the second of computing an expected sum of squares for the plants within each class using a rule of thumb recommeded by Schmalensee (1977).

In 316 of the 459 industries the Census Bureau has withheld data on the total employment within a size class (typically one with three or fewer plants.) In this case, the Census data instead contain the combined employment in this class and another indicated class. To perform a rough separation of the employment in combined classes, we first for each size class used the sample of industrues for which the total employment is reported to estimate the mean and variance of employment/plant as a function of the number of plants in the class. (The mean was assumed to be of the form $a_{0}+a_{1} \log (1+n)$ and the variance of the form $b_{0}+b_{1}(1 / n)$, with the parameters estimated by OLS regressions.) Employment in each of the combined classes were then set so that departures from the predicted means were inversely proportional to the predicted variances, provided that this did not violate the upper and lower bounds on plant size.

The second step procedure essentially consists of assuming that the sizes of the plants within each class are discretely uniformly spread on a range centered on the the mean and with its boundary at the closer of the two endpoints of the size range. $H_{p}$ is estimated simply by taking the sum of the squares of the plant shares for this particular allocation of employees across plants. Schmalensee (1977) reports that this assumption of linear shares within a class seems to give the best estimates of the Herfindahl index in a similar problem.

We do not regard this procedure as an attempt to assign employments to plants, but just as a complicated function which approximates the Herfindahl index given the available

data. To assess the accuracy of this procedure, we constructed a simulated dataset of 5000 industrues. The simulated industries were created by assuming that the plant sizes in industry $i$ consist of $n_{i}$ draws from a lognormal distribution with mean $\mu_{i}$ and standard deviation $\sigma_{i}$. The parameters $n_{i}, \mu_{i}$, and $\sigma_{i}$ were themselves realizations of independent lognormal random variables with means (standard deviations) 527 (1106), 143 (286), and 287 (2101), respectively. These parameters were obtained from sample statistics (and the estimated $H_{p}$ ) of our 459 industry sample. The data produced by the simulations bears a 
superficial resemblance to the actual data, although it tends to contain far more extreme outliers (e.g. industries with over $95 \%$ of employment in a single plant.) We created a simulated dataset modified to preserve confidentiality by combining employment in any size class with two or fewer plants with the employment in the next lower nonempty size class. This modification involved withholding data in $\mathbf{3 2 0 0}$ of the $\mathbf{5 0 0 0}$ industries.

We applied our algorithm to this dataset to produce estimated plant Herfindahls, $\dot{H}_{p}$, and compared these to the true $H_{p}$. On average the estimated Herfindahls were slightly smaller than the true values, the ratio of the means being 1.05. Our principal use for estimates of $H_{\mathrm{p}}$ in the paper is as a part of the computation of $\gamma$ for each industry. Note that if we set $\gamma=\left(G-\hat{H}_{p}\right) /\left(1-\hat{H}_{p}\right)$, where $G=\gamma_{0}+\left(1-\gamma_{0}\right) H_{p}+\epsilon$ with $E\left(\epsilon \mid H_{p}, \hat{H}_{p}\right)=0$ then

$$
E\left(\gamma-\gamma_{0} \mid \dot{\hat{H}_{p}}\right)=\left(1-\gamma_{0}\right) E\left(\frac{H_{p}-\hat{H}_{p}}{1-\hat{H}_{p}} \mid \dot{H}_{p}\right)
$$

Hence, if $E\left(H_{p} \mid \dot{H}_{p}\right)=\dot{H}_{p}$, then our estimates of $\gamma_{0}$ will be unbiased.

One cannot estimate $E\left(H_{p} \mid \hat{H}_{p}\right)$ without making assumptions about the distribution of $H_{p}$. While our simulated $H_{p}$ 's do not match the observed distribution of plant Herfindahls, we hope that they will at least provide results which are indicative of the magnitude of the bias our procedure produces. Over our 5000 industry sample, a OLS regression of $H_{p}$ on $\hat{H}_{\mathrm{p}}$ yields an estimated constant of 0.0003 (t-stat: 1.3 ), with the estimated coefficient on $\hat{H}_{p}$ being 1.04 (t-stat: 228.9 ). Restricting the regression to the observations with $\dot{H}_{p}<0.3$ to eliminate the effect of unreasonable industries gives estimates of 0.0001 ( $t$-stat: 0.5 ) and 1.05 ( $t$-stat: 173.8). Adding a quadratic term to this regression we find the coefficient to be insignificant, suggesting that nonlinearity is not a problem. Regressing the squared error from the linear regression on a constant, $\hat{H}_{p}$, and $\hat{H}_{p}{ }^{2}$ to get an idea of the magnitude of the measurement error in a typical industry gives the estimate $\dot{\sigma}^{2}=0.00003+0.003 \bar{H}_{p}+$ $0.007 \hat{H}_{p}^{2}$.

If we believe these results, then for a typical industry with $\gamma_{0}$ small we will underestimate $\gamma_{0}$ by about $0.05 H_{p}$. Given that the mean of $H_{p}$ is less than 0.03 , this bias is fairly small. To correct this bias, one could simply multiply all of our previous estimates of $H_{p}$ by 1.05 . The correction is not large, however, and given that we have limited confidence in the simulations we decided not to impose it. 


\title{
Appendix C
}

\author{
indus or \\ 2011 Meat pueking plant \\ 2013 Sausages and other propered meat \\ 2015 Poulty sleughtering and procesting \\ 2021 Creamery butter \\ 2022 Chense, netural and procesesed \\ 2023 Dry. condensed, and evaporated dairy product \\ 2024 lee eraam and trozen daterer \\ 2026 Fluid mith \\ 2032 Canned apecintion \\ 2003 Canned truita and vogelablos \\ 2034 Dehydrated frute. vegecubles. and soupa \\ 2035 Piekles, saces, and saled drassinge \\ 2037 Frozen frut and vegelables \\ 2030 Frazen speciation. n.e.c. \\ 2011 flow and other grain mill product \\ 2043 Cereal breaktast loode \\ 2044 Aice milling \\ 2045 Prepared flour mixes and doughe \\ 2048 wot com milting \\ $2047 \mathrm{Dog}$ and cat tood \\ 2048 Prepared fende, n.e.c. \\ 2081 Bread. eake. and related products \\ 2052 Cookines and erackers \\ 2053 Frozen bakery products. exeapt bread \\ 2061 flow cane auger \\ 2082 Cam suger refining \\ 2003 Bent wuges \\ 2004 Candy and ather confectionery product \\ 2068 Chocolale and cocon products \\ 2067 Chowing gum \\ 2065 Saked and roested nuts and seode \\ 2074 Cottoniend oil milt. \\ 2075 Soyboen oil milts \\ 2070 Vegeterble oit mils. n.e.c. \\ 2077 Animal and merine tats and oim \\ 2079 Edibis lata and oits. n.e.c. \\ 2002 Math beveragee \\ 2000 Mat \\ 2004 Wines. brandy, and brandy apirte \\ 2005 Distillad and blanded lapors \\ 2000 botied and cannd woll dinte. \\ 2087 flaworing ontrect and oypes, n.e.e. \\ 2001 canned and ard thi and weolood. \\ 2002 Froch or trosen prepered thin \\ 2003 Rousled cortine \\ 2006 Poten chines and imiler enecks \\ 2007 Manutectured be \\ 2006 Mecarod and wophat: \\ 2009 food preperations. n.e.c. \\ 2111 Clonerove \\ 2121 Coes \\ 2131 Chowing and amoking tobeceo
}

\begin{tabular}{|c|c|c|}
\hline $\begin{array}{r}\text { Emplorment } \\
113.0\end{array}$ & $\begin{array}{r}\text { Plent Hertindah } \\
0.00\end{array}$ & $\begin{array}{r}\text { Gamma } \\
0.042\end{array}$ \\
\hline 70.7 & 0.004 & 0.000 \\
\hline 147.9 & 0.006 & 0.008 \\
\hline 1.7 & 0.045 & 0.147 \\
\hline 33.0 & 0.000 & 0.131 \\
\hline 14.1 & 0.068 & 0.015 \\
\hline 20.3 & 0.003 & 0.001 \\
\hline 72.4 & 0.002 & 0.002 \\
\hline 24.5 & 0.022 & 0.012 \\
\hline 6.1 & 0.008 & 0.044 \\
\hline 10.1 & 0.030 & 0.200 \\
\hline 21.4 & 0.013 & 0.000 \\
\hline 40.0 & 0.011 & 0.070 \\
\hline 37.5 & 0.015 & 0.002 \\
\hline 13.3 & 0.000 & 0.010 \\
\hline 18.0 & 0.084 & 0.018 \\
\hline 4.5 & 0.063 & 0.130 \\
\hline 12.1 & 0.020 & 0.015 \\
\hline 0.6 & 0.060 & 0.137 \\
\hline 13.4 & 0.018 & 0.011 \\
\hline 34.5 & 0.002 & 0.014 \\
\hline 101.0 & 0.008 & 0.001 \\
\hline $\mathbf{4 5 . 3}$ & 0.028 & 0.001 \\
\hline 0.0 & 0.0055 & 0.013 \\
\hline 6.2 & 0.000 & 0.260 \\
\hline 5.5 & 0.107 & 0.000 \\
\hline 7.9 & $0 . \infty 1$ & 0.074 \\
\hline 45.0 & 0.012 & 0.046 \\
\hline 11.0 & 0.107 & 0.038 \\
\hline 5.2 & 0.157 & 0.072 \\
\hline 8.1 & 0.070 & 0.005 \\
\hline 2.8 & 0.002 & 0.180 \\
\hline 7.0 & 0.020 & 0.070 \\
\hline 0.0 & 0.084 & 0.049 \\
\hline 9.1 & 0.000 & 0.010 \\
\hline 9.3 & 0.021 & $0 . \infty 1$ \\
\hline 31.9 & 0.042 & 0.010 \\
\hline 1.4 & 0.072 & 0.238 \\
\hline 13.0 & 0.041 & 0.480 \\
\hline 0.0 & 0.008 & 0.070 \\
\hline 8.0 & 0.002 & 0.005 \\
\hline 8.1 & 0.016 & 0.025 \\
\hline 0.7 & 0.020 & 0.001 \\
\hline 14.2 & 0.007 & 0.080 \\
\hline 10.7 & 0.0028 & 0.042 \\
\hline 33.1 & 0.011 & 0.001 \\
\hline 4.7 & 0.006 & 0.012 \\
\hline 0.4 & 0.021 & 0.001 \\
\hline 50.0 & 0.000 & 0.013 \\
\hline 32.0 & 0.220 & 0.10 \\
\hline 2.5 & 0.107 & 0.150 \\
\hline 3.3 & 0.000 & 0.200 \\
\hline
\end{tabular}




\section{Industry}

2141 Tobacco stomming and redrying

2211 Broadwoven labric mills, cotton

2221 Broadwoven labric mills, manmade fiber and silk

2231 Broadwoven labric mills, wool

2241 Nartow labric mille

2251 Women is hosiery, excepl socks

2252 Hosiery, n.e.c.

2253 Knit ovterwear mills

2254 Knit underwear mills

2257 Weft knit tabric mills

2258 Lace and warp knit labric mills

2259 Knitting mills, n.e.c.

2261 Finishing plants. cotton

2262 Finishing plants. manmado

2269 Finishing plants, n.e.c.

2273 Carpots and rugs

2281 Yam spinning mills

2282 Throwing and winding mills

2284 Thread mills

2295 Casled tabrics, nol rubberized

2296 Tire cord and fabrics

2297 Nonwoven labrics

2298 Cordage and twine

2299 Toxtile goods. n.e.c.

2311 Mon's and boys' suits and coats

2321 Mon's and boys' shirts

2322 Mon's and boys' underwear and nightwear

2323 Men's and boys' neckwear

2325 Mon's and boys' trousers and slacks

2326 Mon's and boys' work clothing

2329 Mon's and boys' clothing. n.e.c.

2331 Women's, misses', and juniors' blouses and shirts

2335 Women's, misses', and juniors' dresses

2337 Women's, misses', and juniors' suits and costs

2339 Women's, misses', and juniors' outerwear, n.e.c.

2341 Women's and children's underwoar

2342 Brassieres, girdles. and allied garments

2353 Hats, cape, and millinery

2361 Girts' and children's dresues and blouses

2369 Girts' and chlldren's outerwoar, n.e.c.

2371 Fur goods

2381 Fabric drese and work gloves

2384 Robes and dreseling gowna

2385 Walerprool outerwoar

2386 Loather and sheep-lined clothing

2387 Apperel batts

2389 Apparel and accessories, n.e.c.

2391 Curtains and draperies

2382 Housefurnishings, n.e.c.

2393 Toxtile bage

2394 Canvas and relaled products

2395 Pleating and stiching

\begin{tabular}{|c|c|c|}
\hline Employment & Plant Herfindahl & Gamma \\
\hline 6.9 & 0.045 & 0.178 \\
\hline 72.3 & 0.025 & 0.170 \\
\hline 88.3 & 0.007 & 0.228 \\
\hline 14.0 & 0.042 & 0.087 \\
\hline 18.5 & 0.011 & 0.074 \\
\hline 29.3 & 0.028 & 0.398 \\
\hline 36.5 & 0.000 & 0.437 \\
\hline 59.0 & 0.012 & 0.065 \\
\hline 19.3 & 0.082 & 0.020 \\
\hline 34.9 & 0.018 & 0.191 \\
\hline 20.5 & 0.014 & 0.116 \\
\hline 3.8 & 0.071 & 0.094 \\
\hline 16.5 & 0.019 & 0.123 \\
\hline 27.9 & 0.022 & 0.188 \\
\hline 11.7 & 0.020 & 0.098 \\
\hline 53.3 & 0.013 & 0.378 \\
\hline 89.0 & 0.005 & 0.284 \\
\hline 18.3 & 0.025 & 0.206 \\
\hline 6.5 & 0.051 & 0.207 \\
\hline 10.3 & 0.020 & 0.001 \\
\hline 5.1 & 0.121 & 0.178 \\
\hline 13.8 & 0.023 & 0.038 \\
\hline 6.9 & 0.017 & 0.034 \\
\hline 16.4 & 0.009 & 0.021 \\
\hline 55.2 & 0.010 & 0.043 \\
\hline 76.7 & 0.004 & 0.062 \\
\hline 17.2 & 0.032 & 0.097 \\
\hline 7.4 & 0.018 & 0.106 \\
\hline 90.3 & 0.004 & 0.064 \\
\hline 33.1 & 0.000 & 0.090 \\
\hline 52.2 & 0.006 & 0.025 \\
\hline 73.4 & .0 .002 & 0.038 \\
\hline 112.7 & 0.001 & 0.098 \\
\hline 55.2 & 0.003 & 0.034 \\
\hline 107.3 & 0.002 & 0.028 \\
\hline 53.7 & 0.006 & 0.053 \\
\hline 13.8 & 0.024 & 0.019 \\
\hline 17.2 & 0.013 & 0.044 \\
\hline 30.9 & 0.007 & 0.030 \\
\hline 40.8 & 0.008 & 0.046 \\
\hline 2.2 & 0.007 & 0.630 \\
\hline 4.8 & 0.027 & 0.102 \\
\hline 8.7 & 0.029 & 0.024 \\
\hline 6.4 & 0.057 & 0.075 \\
\hline 2.1 & 0.034 & 0.100 \\
\hline 10.5 & 0.013 & 0.167 \\
\hline 8.3 & 0.015 & 0.020 \\
\hline 27.1 & 0.000 & 0.025 \\
\hline 50.5 & 0.006 & 0.036 \\
\hline 8.8 & 0.011 & 0.005 \\
\hline 16.7 & 0.005 & 0.010 \\
\hline 14.1 & 0.000 & 0.026 \\
\hline
\end{tabular}


Industry

2396 Automotive and apparel trimmings 2397 Schitfil machine embroideries 2399 Fabricated textile products, n.e.c. 2411 Logging

2421 Sawmille and planing miils. general

$2426 \mathrm{Hardwood}$ dimenaion and flooring mills

2429 Special product sawmills, n.e.c.

2431 Miliwork

2434 Wood kilchen cabinets

2435 Hardwood veneer and plywood

2436 Sottwood veneer and piywood

2439 Structural wood memebers. n.e.c.

2441 Nailod wood boxes and shook

2448 Wood pallels and skids

2449 Wood containers, n.e.c.

2451 Mobile homes

2452 Prelabricated wood buildings

2491 Wood preserving

2493 Reconstituted wood products

2499 Wood prodicts, n.e.c.

2511 Wood household furniture

2512 Upholstered household furniture

2514 Motal household furniture

2515 Mattresses and bodsprings

2517 Wood television and radio cabinets

2519 Household turniture, n.e.c.

2521 Wood otfice turniture

2522 Otfice furniture. except wood

2531 Public building and related furniture

2541 Wood partitions and fixtures

2542 Partitions and fixtures. except wood

2591 Drapery hardware and blinds and shades

2599 Furniture and fixtures. n.e.c.

2611 Pulp mills

2621 Paper mills

2631 Paperboard mills

2652 Sotup paperbaard boxes

2653 Comgated and solid fiber boxes

2655 Fiber cans, drums, and similar products

2656 Sanitary food containers

2657 Folding papartoard boxec

2671 Paper coated and laminated packaging

2672 Paper couted and laminated, n.e.c.

2673 Bags: plastics, laminated, and coated

2674 Bags: uncouted paper and multiwall

2675 Die-cut paper and board

2676 Sanilary paper products

2677 Envolopes

2678 Stationery products

2679 Converted paper products. n.e.c.

2711 Newspapers

2721 Periodicals

\begin{tabular}{|c|c|c|}
\hline Employment & Plant Herfindahl & Gamma \\
\hline 44.2 & 0.016 & 0.074 \\
\hline 5.9 & 0.025 & 0.153 \\
\hline 30.5 & 0.008 & 0.005 \\
\hline 85.8 & 0.001 & 0.062 \\
\hline 148.3 & 0.001 & 0.038 \\
\hline 29.7 & 0.005 & 0.062 \\
\hline 2.2 & 0.009 & 0.374 \\
\hline 89.0 & 0.005 & 0.013 \\
\hline 67.0 & 0.002 & 0.011 \\
\hline 20.5 & 0.008 & 0.050 \\
\hline 38.9 & 0.008 & 0.187 \\
\hline 24.6 & 0.003 & 0.026 \\
\hline 5.9 & 0.009 & 0.018 \\
\hline 25.7 & 0.001 & 0.006 \\
\hline 5.4 & 0.023 & 0.026 \\
\hline 39.9 & 0.005 & 0.037 \\
\hline 25.4 & 0.006 & 0.025 \\
\hline 11.8 & 0.005 & 0.029 \\
\hline 22.0 & 0.011 & 0.029 \\
\hline 56.3 & 0.002 & 0.006 \\
\hline 135.9 & 0.003 & 0.077 \\
\hline 82.1 & 0.004 & 0.130 \\
\hline 30.1 & 0.010 & 0.013 \\
\hline 24.4 & 0.004 & 0.007 \\
\hline 5.9 & 0.072 & 0.010 \\
\hline 5.9 & 0.050 & 0.004 \\
\hline 31.0 & 0.009 & 0.045 \\
\hline 49.7 & 0.036 & 0.050 \\
\hline 21.8 & 0.012 & 0.008 \\
\hline 40.6 & 0.002 & 0.003 \\
\hline 33.5 & 0.007 & 0.011 \\
\hline 20.6 & 0.018 & 0.006 \\
\hline 29.3 & 0.005 & 0.007 \\
\hline 14.2 & 0.051 & 0.047 \\
\hline 129.1 & 0.008 & 0.009 \\
\hline 52.3 & 0.011 & 0.024 \\
\hline 8.7 & 0.011 & 0.037 \\
\hline 105.7 & 0.001 & 0.001 \\
\hline 12.5 & 0.009 & 0.006 \\
\hline 15.8 & 0.047 & 0.028 \\
\hline 50.7 & 0.004 & 0.002 \\
\hline 15.0 & 0.018 & 0.018 \\
\hline 30.9 & 0.017 & 0.010 \\
\hline 36.6 & 0.009 & 0.011 \\
\hline 17.1 & 0.013 & 0.025 \\
\hline 15.7 & 0.011 & 0.011 \\
\hline 38.4 & 0.020 & 0.033 \\
\hline 27.6 & 0.007 & 0.008 \\
\hline 11.2 & 0.021 & 0.025 \\
\hline 28.6 & 0.009 & 0.012 \\
\hline 434.4 & 0.002 & 0.002 \\
\hline 110.0 & 0.005 & 0.067 \\
\hline
\end{tabular}


Industry

2731 Book publishing

2732 Book printing

2741 Miscellaneous publishing

2752 Commercial printing, lithographic

2754 Commercial printing. gravure

2759 Commercial printing, n.e.c.

2761 Manitold businese lorms

2771 Greoting cards

2782 Blankbooks and looseleal binder:

2789 Bookbinding and rolated work

2791 Typeselting

2796 Platomaking services

2812 Akkalies and chlorine

2813 Industrial gases

2816 Inorganic pigments

2819 Industrial inorganic chemicals, n.e.c.

2821 Plastics materials and resins

2822 Synthetic rubber

2823 Cellulosic manmade tibers

2824 Organic fibers. nonceliulosic

2803 Modicinals and botanicals

2834 Pharmacoutical preparations

2835 Diagnostic substances

2836 Biological products, except diagnostic

2841 Somp and other detergents

2842 Polishos and sanitation goods

2843 Surface active agenta

2844 Toilot preparations

2851 Paints and allied products

2861 Gum and wood chemicals

2865 Cyclic crudes and intermediates

2869 Industrial organic chemicals. n.e.c.

2873 Nitrogenous lertilizers

2874 Phosphatic fertilizers

2875 Fertilizers, mixing only

2879 Agricultural chemicals, n.e.c.

2891 Adheaives and tealants

2892 Explosives

2893 Printing Ink

2895 Carbon black

2899 Chemical preparations. n.e.c.

2911 Petroloum refining

295 4 Asphalt paving mixtures and blocks

2952 Asphalt folt and coatings

2992 Lubricating oili and greases

2999 Potroleum and coal products, n.e.c.

3011 Tres and inner tubes

3021 Rubber and plastics footwear

3052 Rubber and plastics hose and beling

3053 Gaskets. packing, and sealing devices

3061 Mechanical rubber goods

3069 Fabricated rubber products, n.e.c.
Employment

70.1

43.5

69.5

403.8

23.8

125.8

53.3

21.5

39.1

29.7

37.6

31.8

5.0

8.1

8.3

72.2

56.3

10.4

10.5

45.4

$\$ 1.6$

131.6

15.4

$\$ 3.3$

31.7

20.6

9.1

57.9

55.2

2.6

22.8

100.3

7.4

9.4

7.5

16.1

20.9

13.8

11.1

1.8

37.8

74.6

14.6

13.5

11.2

1.8

65.4

10.9

23.2

28.4

49.8

54.3
Plant Herfindahl

0.008

0.012

0.005

0.000

0.032

0.001

0.003

0.091

0.007

0.005

0.002

0.002

0.061

0.005

0.041

0.053

0.012

0.063

0.224

0.043

0.042

0.015

0.033

0.023

0.016

0.010

0.017

0.011

0.003

0.041

0.018

0.012

0.025

0.066

0.006

0.038

0.005

0.113

0.005

0.054

0.006

0.011

0.003

0.009

0.007

0.027

0.025

0.060

0.026

$0.01 t$

0.008

0.006
Gamma

0.062

0.011

0.008

0.004

0.016

0.004

0.003

0.037

0.007

0.020

0.014

0.010

0.058

0.011

0.031

0.017

0.029

0.165

0.159

0.140

0.089

0.023

0.059

0.010

0.004

0.018

0.040

0.055

0.007

0.061

0.010

0.069

0.031

0.291

0.020

0.031

0.012

0.003

0.015

0.300

0.006

0.088

0.009

0.010

0.013

0.061

0.038

$-0.013$

0.038

0.016

0.047

0.022 
Industry

300 Unsupported plastics film and sheet

3092 Unsupported plastics profile shapes

3083 Laminated plasbice plate, sheet, and profile shapes

3084 Plastics pipo

3085 Plastics bottlos

3086 Plastlcs loam product

3087 Custom compounding of purchased plastics resins

3088 Plastics plumbing fixtures

3089 Plastics products. n.e.c.

3111 Leather tanning and finishing

313t Footwear cut stock

3142 House slippers

3143 Men's footwear, except athletic

$3 \$ 44$ Women's footwear. excepl athletic

3149 Footwear. except rubber. n.e.c.

3151 Leather gloves and mittens

3161 Luggage

3171 Women's handbags and purses

$3 \$ 72$ Personal loather goods. n.e.c.

3199 Leather goods, n.e.c.

321 \& Flat glass

3221 Glass conlainers

3229 Pressed and blown glass, n.e.c.

3231 Products of purchased glass

3241 Cement. hydraulic

3251 Brick and structural clay tile

3253 Ceramic wall and floor tile

3255 Clay refractorie:

3259 Structural clay products, n.e.c.

3261 Vitreous plumbing fixtures

3262 Vitreous china lable and kitchenware

3263 Semivitreous table and kitchenware

3264 Porcelain electrical supplies

3269 Pottery products. n.e.c.

327 t Concrete block and brick

3272 Concrete products. n.e.c.

3273 Feady-mixed concrete

3274 Lime

3275 Gypsum products

3281 Cut stone and stone products

3291 Abrasive product

3292 Asbestos product

3295 Minorale, ground or treated

3296 Minoral wool

3297 Nonclay retractorie:

3299 Nonmetaliflc mineral products, n.e.c.

33 t 2 Blast furnaces and steel mills

33 t3 Electromelaliurgial product

3315 Steel wire and related products

3316 Cold finishing of steel shapes

3317 Steol pipe and tubes

3321 Gray and ductile iron loundries
Employment

\section{4}

25.2

17.3

12.5

25.1

61.3

17.3

7.5

384.9

14.6

5.0

3.7

31.6

26.6

9.2

3.1

11.4

9.5

7.2

7.1

14.8

41.1

36.3

51.1

19.1

16.6

9.5

6.4

2.1

9.7

5.4

1.8

10.7

10.5

18.6

70.0

96.8

5.7

12.1

12.5

23.4

4.0

8.8

21.5

7.7

7.6

188.1

3.9

24.7

16.4

19.6

82.4
Plant Herfindahl

0.008

0.007

0.025

0.008

0.007

0.004

0.008

0.023

0.001

0.013

0.032

0.104

0.018

0.012

0.025

0.028

0.027

0.021

0.024

0.011

0.055

0.013

0.020

0.005

0.009

0.007

0.039

0.027

0.048

0.041

0.126

0.100

0.030

0.016

0.002

0.001

0.001

0.033

0.013

0.011

0.038

0.107

0.011

0.020

0.020

0.009

0.018

0.072

0.012

0.027

0.010

0.011
Gamma

0.008

0.005

0.005

0.010

0.012

0.004

0.012

0.014

0.005

0.025

0.142

0.068

0.073

0.055

0.088

0.035

0.041

0.144

0.059

0.023

0.019

0.011

0.038

0.002

0.010

0.036

0.023

0.078

0.160

0.014

$-0.001$

0.088

0.044

0.012

0.004

0.012

0.010

0.063

0.013

0.036

0.028

0.009

0.005

0.015

0.042

0.004

0.067

0.148

0.013

0.032

0.038

0.029 


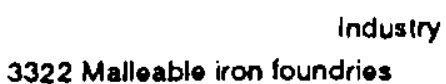

3324 Steol investment loundries

3325 Steol foundries, n.e.c.

3331 Primary copper

3334 Primary aluminum

3339 Primary nonterrous motals. n.e.c.

3341 Socondary nonlerrous motals

3351 Copper rolling and drawing

3353 Aluminum sheot, plate, and foil

3354 Auminum extruded products

3355 Auminum rolling and drawing, n.e.c.

3356 Nonterrous rolling and drawing. n.e.c.

3357 Nonterrous wiredrawing and insulating

3363 Aluminum die-castings

3364 Nonterrous die-casting, except aluminum

3365 Aluminum foundries

3366 Copper foundries

3369 Nonferrous foundries, n.e.c.

3398 Motal hoal treating

3399 Primary motal products. n.e.c.

3411 Metal cans

3412 Motal barrols. drums, and pails

3421 Cutlery

3423 Hand and edge lools. n.e.c.

3425 Saw blades and handsaws

3429 Hardware. n.e.c.

3431 Metal sanitary ware

3432 Plumbing fixture fittings and trim

3433 Heating equipment. except electric

3441 Fabricated struclural metal

3442 Motal doors, sash, and trim

3443 Fabricated plate work (boiler shops)

3444 Shoot motal work

3446 Architectural metal work

3448 Profabricated metal buildings

3449 Miscellaneous molal work

3451 Screw machine products

3452 Bolts. nuts. rivets, and washers

3462 Iron and steol forgings

3463 Nonferrous forgings

3465 Automotive stampings

3466 Crowns and closures

3469 Motal stampings, n.e.c.

3471 Plating and polishing

3479 Metal costing and allied services

3482 Small arms ammunition

3483 Ammunition. except for small arms, n.e.c.

3484 Small arms

3489 Ordnance and accessories. n.e.c.

3491 Industrial valves

3492 Fluid power valves and hose fittinge

3493 Steol springs, except wire

\begin{tabular}{|c|c|c|}
\hline Employment & Plant Horfindahl & Gamma \\
\hline 4.2 & 0.197 & 0.072 \\
\hline 20.3 & 0.040 & -0.000 \\
\hline 22.9 & 0.012 & 0.040 \\
\hline 3.3 & 0.135 & 0.194 \\
\hline 17.3 & 0.050 & 0.053 \\
\hline 11.0 & 0.044 & 0.004 \\
\hline 12.5 & 0.008 & 0.016 \\
\hline 22.6 & 0.029 & 0.018 \\
\hline 26.1 & 0.063 & 0.009 \\
\hline 30.7 & 0.013 & 0.001 \\
\hline 0.9 & 0.084 & 0.031 \\
\hline 17.9 & 0.031 & 0.016 \\
\hline 64.9 & 0.008 & 0.018 \\
\hline 28.1 & 0.010 & 0.021 \\
\hline 12.9 & 0.010 & 0.036 \\
\hline 26.3 & 0.008 & 0.021 \\
\hline 8.2 & 0.007 & 0.012 \\
\hline 4.0 & 0.117 & 0.100 \\
\hline 18.0 & 0.004 & 0.026 \\
\hline 13.8 & 0.105 & 0.059 \\
\hline 39.4 & 0.006 & 0.009 \\
\hline 8.7 & 0.014 & 0.042 \\
\hline 10.5 & 0.039 & 0.056 \\
\hline 41.9 & 0.008 & 0.008 \\
\hline 7.7 & 0.039 & 0.039 \\
\hline 85.2 & 0.007 & 0.008 \\
\hline 8.0 & 0.064 & 0.030 \\
\hline 17.1 & 0.023 & 0.003 \\
\hline 20.5 & 0.008 & 0.000 \\
\hline 80.0 & 0.006 & 0.004 \\
\hline 74.7 & 0.000 & 0.003 \\
\hline 74.7 & 0.004 & 0.010 \\
\hline 100.2 & 0.001 & 0.003 \\
\hline 28.0 & 0.004 & 0.004 \\
\hline 25.8 & 0.009 & 0.006 \\
\hline 22.9 & 0.006 & 0.014 \\
\hline 42.7 & 0.002 & 0.027 \\
\hline 52.0 & 0.006 & 0.029 \\
\hline 26.8 & 0.017 & 0.024 \\
\hline 7.3 & 0.082 & 0.022 \\
\hline 119.8 & 0.013 & 0.177 \\
\hline 8.1 & 0.056 & 0.039 \\
\hline 95.5 & 0.002 & 0.018 \\
\hline 71.1 & 0.001 & 0.012 \\
\hline 41.5 & 0.002 & 0.014 \\
\hline 9.0 & 0.184 & -0.004 \\
\hline 41,5 & 0.041 & 0.000 \\
\hline 13.3 & 0.067 & 0.080 \\
\hline 23.9 & 0.168 & 0.004 \\
\hline 45.9 & 0.009 & 0.006 \\
\hline 27.9 & 0.010 & 0.037 \\
\hline 5.0 & 0.024 & 0.048 \\
\hline
\end{tabular}


3537 industrial trucks and tractors

3541 Machine tools, metal culting types

3542 Machine tools. motal forming typos

3543 Industrial paftiorns

3544 Special dies, tools, jigs, and fixtures

3545 Machine rool accessories

3546 Power-driven handiools

3547 Rolling mill machinery

3548 Woiding apparatus

3549 Metalworking machinery, n.e.c.

3552 Textile machinery

3553 Woodworking machinery

3554 Paper industries machinery

3555 Printing trades machinery

3556 Food products machinory

3559 Special industry machinery, n.e.c.

3561 Pumps and pumping equipment

3562 Ball and rollor bearings

3563 Air and gas compressors

3564 Blowers and fans

3565 Packaging machinery

3566 Spoed changers, drives, and goars

3567 industrlal turnaces and ovens

3568 Power trenamiaston equipment, n.e.c.

3569 General induatrial machinery, n.e.c.

3571 Electronio computere

3572. Computer storage devices

3575 Computer terminate

3577 Computer peripheral equipment, n.e.c. 


$$
\text { Industry }
$$

3592 Carburetors. pistons, rings, and valves 3593 Fluid power cylinders and actuators 3594 Fluid power pumpe and motors 3596 Scales and balances, except laboratory 3599 Industrial machinery. n.e.c. 3612 Transtormers, except electronic 3613 Switchgear and switchboard apparatus 3621 Motors and generators 3624 Carbon and graphite products 3625 Rolays and industrial controls 3629 Electrical industrial apparatus. n.e.c. 3631 Household cooking equipment 3632 Household relrigeralors and lreazers 3633 Household laundry equipment 3634 Eloctric housowares and fans 3635 Household vacuum cleaners 3639 Household appliances, n.e.c. 3641 Eloctric lamp bulbs and tubos 3643 Current-carrying wiring devices 3644 Noncurrent-carrying wiring devices 3645 Pesidential lighting fixtures 3646 Commercial lighting fixtures 3647 Vehicular lighting equipment 3648 Lighting equipment, n.e.c. 3651 Household audio and video equipment 3652 Prerecorded records and tapes 3661 Tolephone and telegraph apparatus

3603 Radio and television communications equipment 3669 Communications equipment, n.e.c.

3671 Electron tubes

3672 Printed circuit boards

3674 Somiconductors and related devices

3675 Eloctronic capacitors

3676 Electronic resistors

3677 Electronic coils and transformers

3678 Electronic connectors

3679 Electronic components, n.e.c.

3691 Storage batterios

3692 Primary batteries, dry and wot

3694 Engine electrical equipment

3695 Magnotic and optlesl recording media

3699 Electricel equipment and supplles, n.e.c.

3711 Motor vehiches and car bodies

3713 Truck and bus bodies

3714 Motor vehiclo parts and accessories

3715 Truck trailers

3716 Motor homes

3721 Aircratt

3724 Aircratt engines and engine parts

3728 Aircratt parts and equipment, n.e.c.

3731 Ship building and repairing

3732 Boat building and repairing

\begin{tabular}{|c|c|c|}
\hline Employment & Plant Hertindahl & Gamma \\
\hline 21.7 & 0.038 & 0.042 \\
\hline 20.2 & 0.052 & 0.025 \\
\hline 14.8 & 0.034 & 0.003 \\
\hline 6.7 & 0.027 & 0.023 \\
\hline 228.5 & 0.000 & 0.005 \\
\hline 32.2 & 0.018 & 0.021 \\
\hline 44.8 & 0.010 & 0.008 \\
\hline 74.6 & 0.008 & 0.021 \\
\hline 9.8 & 0.033 & 0.042 \\
\hline 66.6 & 0.010 & 0.008 \\
\hline 14.5 & 0.017 & 0.010 \\
\hline 21.9 & 0.050 & 0.030 \\
\hline 25.7 & 0.107 & 0.035 \\
\hline 16.7 & 0.128 & 0.124 \\
\hline 25.1 & 0.019 & 0.107 \\
\hline 11.3 & 0.182 & .0 .009 \\
\hline 16.0 & 0.061 & 0.030 \\
\hline 22.2 & 0.027 & 0.033 \\
\hline 47.9 & 0.017 & 0.009 \\
\hline 21.5 & 0.023 & 0.012 \\
\hline 22.5 & 0.000 & 0.027 \\
\hline 22.7 & 0.022 & 0.018 \\
\hline 15.5 & 0.139 & 0.022 \\
\hline 14.4 & 0.017 & 0.010 \\
\hline 30.9 & 0.035 & 0.016 \\
\hline 13.3 & 0.039 & .0 .008 \\
\hline 112.3 & 0.021 & 0.009 \\
\hline 126.0 & 0.015 & 0.021 \\
\hline 21.9 & 0.017 & 0.030 \\
\hline 28.4 & 0.057 & 0.043 \\
\hline 66.6 & 0.005 & 0.041 \\
\hline 184.6 & 0.014 & 0.064 \\
\hline 21.7 & 0.023 & 0.029 \\
\hline 15.7 & 0.022 & 0.016 \\
\hline 23.8 & 0.000 & 0.018 \\
\hline 42.8 & 0.017 & 0.036 \\
\hline 162.6 & 0.008 & 0.022 \\
\hline 24.2 & 0.017 & 0.010 \\
\hline 10.7 & 0.045 & 0.049 \\
\hline 67.3 & 0.045 & 0.054 \\
\hline 25.6 & 0.028 & 0.085 \\
\hline 60.3 & 0.008 & 0.015 \\
\hline 281.3 & 0.016 & 0.127 \\
\hline 37.8 & 0.009 & 0.008 \\
\hline 389.6 & 0.006 & 0.089 \\
\hline 27.5 & 0.013 & 0.014 \\
\hline 15.1 & 0.055 & 0.150 \\
\hline 268.2 & 0.053 & 0.023 \\
\hline 139.6 & 0.042 & 0.047 \\
\hline 188.2 & 0.029 & 0.032 \\
\hline 120.2 & 0.080 & 0.014 \\
\hline 57.2 & 0.005 & 0.046 \\
\hline
\end{tabular}


Industry

3743 Railroad equipment

3751 Motorcycles, bicycles, and parts 3761 Guided missiles and space vehicles 3764 Space propuizlon units and parts 3769 Space vehtcle equipment, n.e.c. 3792 Travel trailers and campers 3795 Janks and tank components 3799 Transportation equipment, n.e.c. 3812 Search and navigation equipment 3821 Laboratory apparalus and furniture 3822 Environmental controls 3823 Process control instruments 3824 Fluid meters and counting devices 3825 Instruments to measure electricity 3826 Anahytical instruments 3827 Optical instruments and lenses

\$29 Measuring and contolling devices, n.e.c.

\$1 Surgical and medical instruments

2 Surgical appliances and supplies

3 Denta vquipment and supplies

$4 X$.ray apparatus and tubes

$\$ 5$ Electromedical equipment j251 Opthalmic goods 3861 Photographic equipment and supplios 3873 Watches, clocks, watchcases. and parta 3911 Jowelry, procious metal 3914 Silverware and plated ware 3915 Jewelers' materials and lapidary work 3931 Musical instruments 3942 Dolls and stutiod toys 3944 Games. toys, and children's vohicies

- : 9 Sporting and athlotic goods, n.e.c.

Pons and mochanical pencils

Lead poncils and ant goods

Marking devices

i Carbon paper and inked ribbons

:1 Costume jeweiry

3965 Fasteners, buttons, neadlos, and pins

3991 Brooms and brustios

3993 Signs and advertising spocialties 3995 Burial caskots

$3996 \mathrm{H}$ ard surface noor coverings, n.e.c. 3999 Manufacturing industries, n.e.c.

\begin{tabular}{rrr} 
Employment & Plant Herfindahi & Gamma \\
22.1 & 0.085 & 0.123 \\
7.4 & 0.077 & 0.010 \\
166.7 & 0.046 & 0.249 \\
31.8 & 0.145 & 0.112 \\
15.1 & 0.157 & 0.005 \\
17.2 & 0.011 & 0.087 \\
16.7 & 0.157 & 0.023 \\
15.4 & 0.015 & 0.021 \\
369.4 & 0.011 & 0.039 \\
17.1 & 0.020 & 0.000 \\
26.5 & 0.035 & 0.011 \\
53.3 & 0.010 & 0.017 \\
10.1 & 0.032 & 0.022 \\
85.2 & 0.014 & 0.031 \\
31.2 & 0.014 & 0.039 \\
20.1 & 0.027 & 0.061 \\
41.0 & 0.015 & 0.004 \\
73.1 & 0.007 & 0.011 \\
78.5 & 0.005 & 0.005 \\
14.6 & 0.017 & 0.022 \\
8.7 & 0.049 & 0.017 \\
29.2 & 0.021 & 0.025 \\
24.2 & 0.020 & 0.027 \\
88.0 & 0.067 & 0.174 \\
11.8 & 0.031 & 0.005 \\
35.5 & 0.005 & 0.095 \\
6.9 & 0.065 & 0.049 \\
7.1 & 0.025 & 0.298 \\
12.2 & 0.017 & 0.014 \\
4.4 & 0.027 & 0.086 \\
30.9 & 0.017 & 0.011 \\
53.6 & 0.005 & 0.003 \\
8.4 & 0.048 & 0.030 \\
5.6 & 0.045 & 0.030 \\
7.5 & 0.007 & 0.005 \\
7.3 & 0.035 & 0.008 \\
22.2 & 0.017 & 0.320 \\
9.8 & 0.018 & 0.042 \\
12.3 & 0.014 & 0.007 \\
\hline 6.3 & 0.001 & 0.006 \\
\hline 6.3 & 0.026 & 0.050 \\
\hline 139 & 0.097 \\
\hline 1.6 & 0.008
\end{tabular}

